\title{
Los micromamíferos (Lagomorpha, Eulipotyphla y Rodentia) del yacimiento del Pleistoceno Medio de Cuesta de la Bajada (Teruel, España): Estudio sistemático y consideraciones paleoambientales
}

\section{The micromammals (Lagomorpha, Eulipotyphla and Rodentia) from the Middle Pleistocene site of Cuesta de la Bajada (Teruel, Spain): Systematic study and paleoenvironmental considerations}

\author{
C. Sesé ${ }^{1}$, E. Soto ${ }^{1}$, M. Santonja ${ }^{2}$, A. Pérez-González², M. Domínguez-Rodrigo ${ }^{3}$ \\ 1 Dpto. Paleobiología. Museo Nacional de Ciencias Naturales. C.S.I.C., C/ José Gutiérrez Abascal 2. 28006 Madrid, España. Email: \\ c.sese@mncn.csic.es \\ 2 CENIEH (Centro Nacional de Investigación sobre la Evolución Humana), Paseo Sierra de Atapuerca 3. 09002 Burgos, España \\ 3 Departamento de Prehistoria, Universidad Complutense, Prof. Aranguren s/n. 28040 Madrid, España
}

\section{RESUMEN}

La asociación de micromamíferos determinada en este trabajo es la siguiente: Lagomorpha: Oryctolagus cuniculus; Eulipotyphla: Crocidura cf. russula, cf. Sorex sp., Neomys sp., Soricidae indet. y Talpa sp.; y Rodentia: Eliomys quercinus, Apodemus cf. sylvaticus, Cricetulus (Allocricetus) bursae, Arvicola aff. sapidus, Microtus (Iberomys) brecciensis y Microtus (Terricola) duodecimcostatus. Es una asociación característica del Pleistoceno Medio. El estadio evolutivo de Cricetulus (A.) bursae, Arvicola aff. sapidus y Microtus (I.) brecciensis le aproximan a las poblaciones de dichas especies de algunos yacimientos de la Península Ibérica del Pleistoceno Medio avanzado, pero no final, lo que es acorde con las dataciones numéricas obtenidas en el yacimiento (243-337 ka) que le sitúan en el MIS 8 o 9. Los micromamíferos indican la predominancia de los espacios abiertos con abundante vegetación herbácea y arbustiva, en los que podría haber también alguna zona arbolada. El clima que indican es de tipo mediterráneo, similar al actual en la zona o quizás algo más benigno y más húmedo.

Palabras clave: Micromamíferos; Lagomorpha; Eulipotyphla; Rodentia; Pleistoceno Medio; Yacimiento de Cuesta de la Bajada; Teruel; España.

\section{ABSTRACT}

The micromammal association established in this work is the following: Lagomorpha: Oryctolagus cuniculus; Eulipotyphla: Crocidura cf. russula, cf. Sorex sp., Neomys sp., Soricidae indet. and Talpa sp.; and Rodentia: Eliomys quercinus, Apodemus cf. sylvaticus, Cricetulus (Allocricetus) bursae, Arvicola aff. sapidus, Microtus (Iberomys) brecciensis and Microtus (Terricola) duodecimcostatus. This association is characteristic of the Middle Pleistocene. The morphological state of Cricetulus (A.) bursae, Arvicola aff. sapidus and Microtus ( $I$.) brecciensis allows to place it in the advanced, but not final, Middle Pleistocene, which agrees with the numerical data of the site (243-337 ka) that places it in the MIS 8 or 9 . The micromammals indicate the predominance of the open spaces with abundant vegetation mainly of herbaceous and bushes but also with some areas with trees. The climate would be of Mediterranean type, similar to the actual or perhaps a little milder and more humid.

Keywords: Micromammals; Lagomorpha; Eulipotyphla; Rodentia; Middle Pleistocene; Cuesta de la Bajada site; Teruel; Spain

Recibido el 24 de febrero de 2016 / Aceptado el 22 de septiembre de 2016 / Publicado online el 24 de noviembre de 2016

Citation / Cómo citar este artículo: C. Sesé et al. (2016). Los micromamíferos (Lagomorpha, Eulipotyphla y Rodentia) del yacimiento del Pleistoceno Medio de Cuesta de la Bajada (Teruel, España): Estudio sistemático y consideraciones paleoambientales. Estudios Geológicos 72(2): e057. http://dx.doi.org/10.3989/egeol.42424.405.

Copyright: ( 2016 CSIC. This is an open-access article distributed under the terms of the Creative Commons Attribution-Non Commercial (by-nc) Spain 3.0 License. 


\section{Introducción}

\section{Antecedentes}

El yacimiento de Cuesta de la Bajada (Teruel) reúne una industria del Paleolítico Medio antiguo junto con una rica y variada asociación de macromamíferos y micromamíferos. Fue descubierto por Étienne Moissenet, que lo dio a conocer, situándolo estratigráficamente y biostratigráficamente en base a la asociación de mamíferos bien en el Pleistoceno Medio muy avanzado o en el Pleistoceno Superior, dentro de un amplio estudio sobre las terrazas aluviales de la fosa de Teruel, en la $2^{\text {a }}$ Reunión del Cuaternario Ibérico celebrada en Madrid en 1989 que se publicó posteriormente (Moissenet, 1993). Una vez visto el potencial paleontológico y arqueológico del yacimiento, E. Moissenet se puso en contacto con Manuel Santonja y Alfredo Pérez-González, que han codirigido las excavaciones desde 1990 hasta 2011. Como resultado de todos estos años de estudios multidisciplinares en el yacimiento, se han realizado diversas publicaciones en las que se han dado a conocer datos preliminares sobre la geología, estratigrafía, industria y mamíferos del yacimiento (Santonja et al., 1990, 1992, 1994, 1996 y 2000; Santonja \& Pérez-González 2001 y 2010) y, recientemente, una síntesis sobre la industria, fauna, tafonomía y dataciones numéricas realizadas con diversas técnicas, que revela la importancia del yacimiento dentro del contexto del Paleolítico Medio en Europa (Santonja et al., 2014). Hay además un trabajo sobre la tafonomía del yacimiento, en relación con la subsistencia de los homínidos en Europa durante el Pleistoceno Medio, en el que se pone de manifiesto que estos fueron los principales agentes de caza y acumulación de restos de macromamíferos en Cuesta de la Bajada (Domínguez-Rodrigo et al., 2015).

La primera etapa de las excavaciones en el yacimiento tuvo lugar entre 1990 y 1994 en el Sector Oeste, en las que se obtuvo industria lítica y restos de fauna en posición derivada, cuyo estudio aportó el conocimiento básico del yacimiento y su entorno (Santonja \& Pérez-González, 2001). Santonja et al. (1994) publican la estratigrafía del yacimiento en la que señalan que la fauna de macromamíferos y la industria lítica se encontraron fundamentalmente en los niveles 16 a 19 (Figura 1: d). Tal como señalan dichos autores (o.c.) del sedimento fino extraído, fundamentalmente del nivel 16, se seleccionó una fracción en torno al 10\% que se lavó con agua, aunque también se cribó en seco cierta cantidad de sedimento de los niveles fluviales infrayacentes (17/18/19) sin precisar. Sin embargo, a pesar de la gran cantidad de sedimento cribado, se han encontrado relativamente muy pocos restos identificables de microvertebrados, la mayoría procedentes del nivel 16 .

Entre 1999 y 2011 se realizaron sendas excavaciones en el Sector Este del yacimiento en sedimentos más finos fluvio-lacustres, estratigráficamente por encima de los niveles mencionados anteriormente del Sector Oeste, en los que se distinguieron cuatro niveles de muro a techo: CB3, CB2, CB1 y P (Santonja et al., 2014), y de los que se lavó gran cantidad de sedimento para la obtención de microvertebrados (Figura 1: c). La gran mayoría de los restos de micromamíferos objeto de este estudio provienen del sedimento procesado en este segundo ciclo de excavaciones realizadas en el Sector Este en los niveles mencionados.
Los micromamíferos encontrados e identificados inicialmente por E. Moissenet (Santonja et al., 1990 y 1992; Moissenet, 1993), son los siguientes: Lagomorpha: Oryctolagus cf. cuniculus; Eulipotyphla: Erinaceus sp. y Crocidura sp.; Rodentia: Apodemus sylvaticus, Allocricetus bursae, Arvicola cf. sapidus, Microtus brecciensis-dentatus y Pitymys cf. pyrenaicus. Según Santonja et al. (1992), E. Moissenet obtuvo esta fauna de micromamíferos a finales de los años ochenta lavando dos toneladas de sedimento a lo largo del frente de la cantera, es decir que parecen provenir de algunos niveles del Sector Este que estaban expuestos en corte vertical, ya que los del Sector Oeste estaban entonces cubiertos por arenas.

Durante las campañas de excavación de 1992 a 2011 se han lavado 23 toneladas de sedimento procedente del mismo con el resultado de la obtención de una variada y rica microfauna con restos de gasterópodos, peces, anfibios, reptiles y micromamíferos, así como restos de microlascas. Entre los micromamíferos, hay representación de todos los taxones mencionados anteriormente, excepto Erinaceus sp., del que no se ha vuelto a encontrar ningún resto, y sin embargo se han encontrado varios taxones más que no habían sido citados pertenecientes a los órdenes Eulipotyphla y Rodentia. Recientemente Santonja et al. (2014) establecieron en el yacimiento la asociación de micromamíferos siguiente: Lagomorpha: Oryctolagus cf. cuniculus; Eulipotyphla: Sorex sp. y Crocidura cf. russula; Rodentia: Eliomys quercinus, Apodemus cf. sylvaticus, Cricetulus (Allocricetus) bursae, Microtus brecciensis, Microtus $\mathrm{cf}$. duodecimcostatus y Arvicola aff. sapidus.

En el presente trabajo realizamos por primera vez el estudio sistemático de los micromamíferos del yacimiento procedentes de las campañas de excavación mencionadas, así como algunas precisiones de interés sistemático, evolutivo, biostratigráfico y paleoecológico.

\section{Geología, estratigrafía, macromamíferos, cronología, arqueología y tafonomía}

El yacimiento de Cuesta de la Bajada se sitúa en una cantera de clasificación de áridos en la orilla izquierda del río Alfambra, muy cerca de Teruel, en terrenos propios del municipio en los que desde 1984 hay una industria dedicada a la clasificación de gravas y arenas extraídas en canteras próximas.

El río Alfambra drena parcialmente la depresión neógena de Teruel que estructuralmente se dispone oblicuamente a la Cordillera Ibérica (Santonja et al., 2014). De las 10 terrazas fluviales que se han distinguido en el valle del río Alfambra, el yacimiento de Cuesta de la Bajada está situado en la T4 (terraza de Cuesta de la Bajada) que tiene una cota de $+50-53$ m con respecto al cauce actual del río, y que ocupa una posición morfológica media dentro del sistema de terrazas del valle, que va desde los niveles a +2-3 m (T10, llanura aluvial), hasta los $+103-104$ m (T1, Torre de la Telefónica, El Planuzar) (Moissenet, 1993; Santonja et al., 1990, 1992 y 2014). El yacimiento se sitúa a unos $18 \mathrm{~m}$ sobre el muro conocido de la secuencia fluvial de la terraza T4 (Santonja et al., 2014). Esta terraza tiene la particularidad de que ha sufrido un proceso local de engrosamiento por subsidencia sinsedimentaria de al menos $50 \mathrm{~m}$, ya que la base 
(a)

(b)
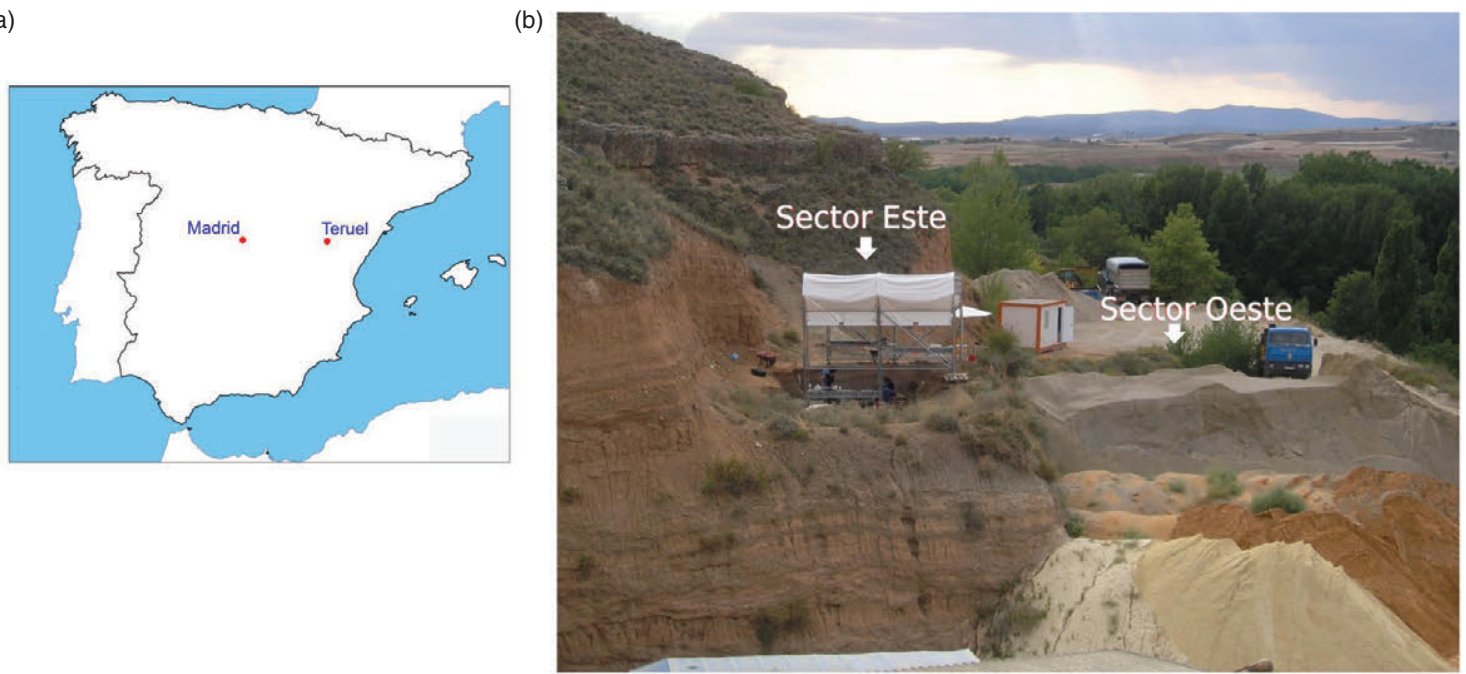

(c)

(d)
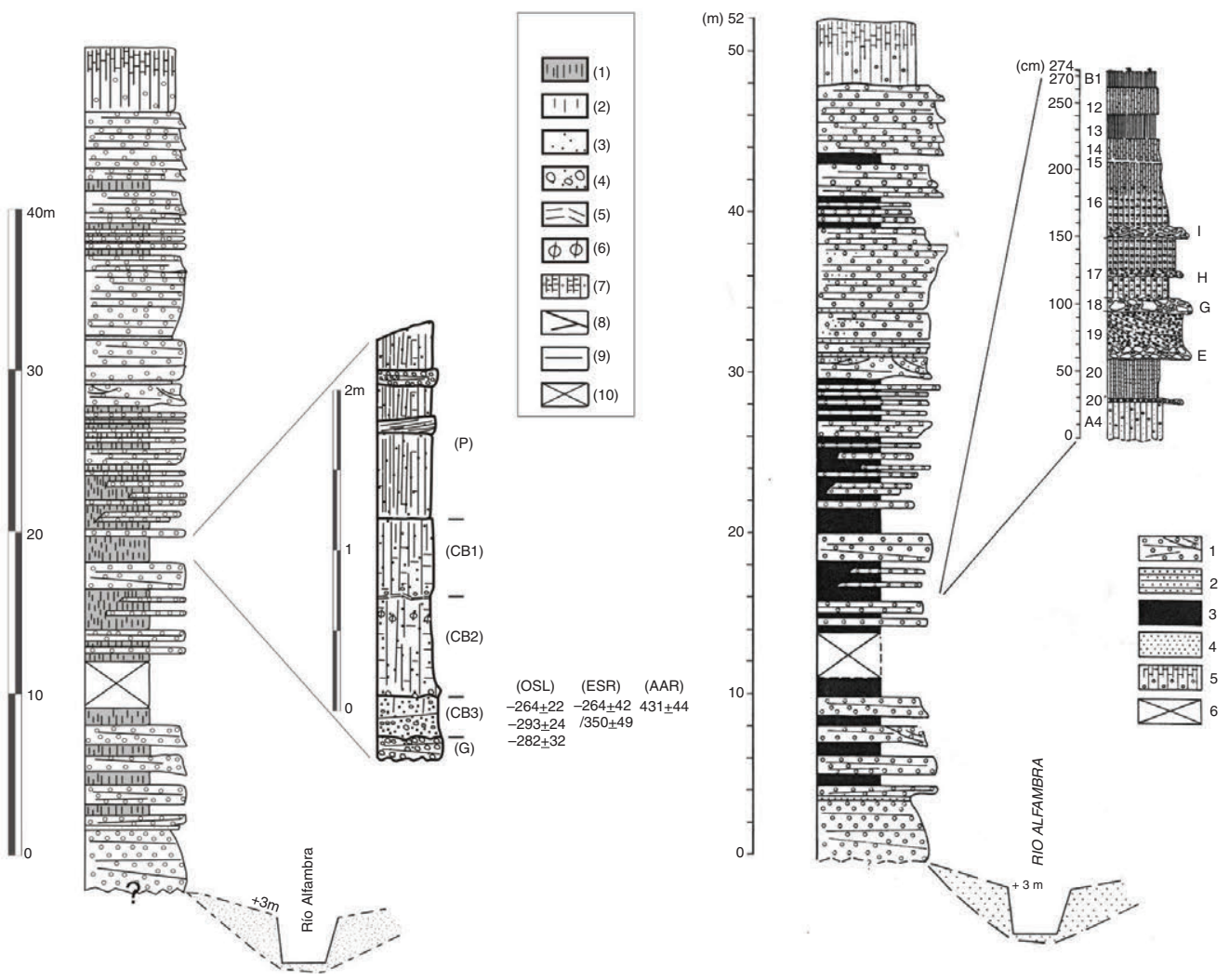

Fig. 1.-a: Situación del yacimiento de Cuesta de la Bajada (Teruel) en la Península Ibérica. b: Vista general del yacimiento de Cuesta de la Bajada con la ubicación del Sector Este y Sector Oeste (Santonja et al., 2014). c: Sección estratigráfica de la terraza T4 del río Alfambra y detalle de la secuencia estratigráfica en el Sector Este de los niveles G, CB3, CB2, CB1 y P del yacimiento de Cuesta de la Bajada, según Santonja et al. (2014). Las dataciones obtenidas por OSL, ESR y AAR en el nivel CB3 se indican en miles de años a la derecha de la columna estratigráfica. Leyenda: (1): fangos; (2): arcillas y limos; (3): arenas y gránulos; (4): gravas; (5) nivel de oxidación; (6): concreción de carbonato; (7): coluvial y suelo; (8): estratificación cruzada; (9) contacto estratigráfico; (10) sección cubierta. d: Sección estratigráfica de la terraza T4 del río Alfambra y detalle de la secuencia estratigráfica en el Sector Oeste de los niveles A4, 20 al 12 y B1 del yacimiento de Cuesta de la Bajada, según Santonja et al. (1994 y 2000). I, H, G y E: pavimentos de gravas y eventualmente bloques. Leyenda: (1): gravas y arenas con estratificación cruzada; (2): arenas con laminación horizontal; (3): fangos, (4): arenas masivas; (5): depósitos laterales y horizonte edáfico carbonatado; (6): sección cubierta. 
que aflora de la terraza está solapada por la llanura aluvial limo -areno -arcillosa del río Alfambra (Santonja et al., 2014).

Santonja et al. (2014) realizan las siguientes precisiones: Los niveles distinguidos en el Sector Este excavado en los últimos años en el yacimiento están asociados a una pequeña depresión, por deformación, situada entre una secuencia cíclica de barras de gravas y fangos de llanura de inundación. El nivel inferior G, de gravas fundamentalmente, es estéril tanto arqueológica como paleontológicamente. El relleno subsiguiente del yacimiento propiamente dicho está formado por $1,5 \mathrm{~m}$ constituido por tres capas de muro a techo: $\mathrm{CB} 3, \mathrm{CB} 2$ y $\mathrm{CB} 1$, las dos últimas claramente granodecrecientes, compuestas fundamentalmente de arenas y arcillas en distintas proporciones que corresponden a medios de sedimentación de baja energía. Por último, $\mathrm{P}$ es el nivel de facies de llanura de inundación, con espesor de $1 \mathrm{~m}$, que cierra esta secuencia (Figura 1: c).

Se ha realizado un estudio multidisciplinar de la cronología, fundamentalmente del nivel CB3, utilizando diversas técnicas con los siguientes resultados según Santonja et al. (2014): Las dataciones obtenidas por Luminiscencia Ópticamente Estimulada (Optically Stimulated Luminescence-OSL) en grano simple en cuarzo en el nivel CB3, aportan edades de $293 \pm 24 \mathrm{ka}$ y $264 \pm 22 \mathrm{ka}$, con una edad media estimada para las cuatro muestras de $278 \pm 16 \mathrm{ka}$. Para el nivel CB1 se obtuvo una edad de $282 \pm 32 \mathrm{ka}$. Las dataciones por Espectroscopia de Resonancia de Espín Electrónico (Electronic Spin Resonance Spectroscopy-ESR) en cuarzo sedimentario en el nivel CB3 son: $350 \pm 49$ ka y $264 \pm 42$ ka. Por último se realizó el análisis por Racemización de Aminoácidos (AAR) sobre cuatro molares de Equus chosaricus, obteniendo unas edades de 378; 478; 455 y $413 \mathrm{ka}$, respectivamente, con una edad estimada para las cuatro muestras de $431 \pm 44 \mathrm{ka}$. Como puede observarse, los datos radiométricos por OSL y ESR son bastante coherentes entre sí, sin embargo los datos por AAR muestran una mayor dispersión entre ellos y son sistemáticamente más antiguos que las fechas obtenidas por los métodos anteriores. Sin embargo, según dichos autores (o.c.), si se tienen en cuenta las edades por series de U/ Th de la terraza equivalente de Los Baños (T4), la edad más plausible para el yacimiento de Cuesta de la Bajada seria del MIS 8 o 9 (243-337 ka).

En cuanto a la estratigrafía de los niveles excavados durante los primeros años en el Sector Oeste del yacimiento (Figura 1: d), además de lo expuesto anteriormente, se pueden consultar más detalles en Santonja et al. (1994 y 2000).

La asociación de macromamíferos del yacimiento de Cuesta de la Bajada está formada por los siguientes taxones según Santonja et al. (2014): Carnivora: Canis lupus; Proboscidea: Elephas (Palaeoloxodon) antiquus; Perissodactyla: Stephanorhinus cf. hemitoechus y Equus chosaricus; Artiodactyla: Cervus elaphus, Bos primigenius, Rupicapra rupicapra y Capra sp. Es una asociación característica del Pleistoceno Medio.

Del estudio de la industria y la tafonomía de los macromamíferos del yacimiento se desprenden las siguientes conclusiones según Santonja et al. (2014) y Domínguez-Rodrigo et al. (2015) respectivamente: En primer lugar, Cuesta de la Bajada es uno de los yacimientos en los que se documenta industria lítica encuadrable en la tradición del Paleolítico Medio europeo.
En segundo lugar, hay muchas evidencias que muestran que los homínidos cazaron y procesaron la mayoría de los esqueletos de macromamíferos, sobre todo de équidos y cérvidos, especialmente en el nivel CB3, y constituye uno de los mejores ejemplos de los comportamientos predatorios humanos documentados en el registro paleontológico y arqueológico del Pleistoceno Medio en Europa.

\section{Metodología}

Durante las campañas de excavación llevadas a cabo en el yacimiento hasta 2011, gran parte del sedimento se sometió al proceso de lavado-tamizado con agua, para su disgregación y la eliminación de la matriz arcilloso-limosa, obteniendo un concentrado que, aunque por lo general muy detrítico, está enriquecido en restos fósiles. Este proceso requiere varios pasos: primero se seca el sedimento, a continuación se sumerge bruscamente en agua para facilitar su desintegración, y finalmente se lava con agua a presión en la mesa de lavado que tiene un juego de tres tamices, de $10 \mathrm{~mm}, 2,5 \mathrm{~mm}$, y el más fino de $0,5 \mathrm{~mm}$ de luz de malla. Una vez obtenido el concentrado en distintas fracciones del sedimento, se procedió a triar de visu el sedimento conseguido en las cribas con $10 \mathrm{~mm}$ y $2,5 \mathrm{~mm}$ de luz de malla, y el más fino procedente de la criba de $0,5 \mathrm{~mm}$ se trió mediante una lupa binocular o microscopio.

Se han lavado en total $23.000 \mathrm{~kg}$ de sedimento. Las cantidades de sedimento procesadas por niveles son desiguales por varias razones: por una parte dichos niveles no tienen la misma potencia, por otra, el sedimento para el lavado dependía del nivel excavado más extensamente durante la campaña, y finalmente, ante la imposibilidad de poder procesar la totalidad del sedimento procedente de cada excavación por su gran magnitud, una vez muestreados y comprobada la similitud de las asociaciones faunísticas de los diferentes niveles, se optó por estimar la riqueza en restos fósiles de cada uno de ellos y procesar mayor cantidad de sedimento en los niveles considerados más ricos en restos fósiles. En el Sector Este, del nivel P se han lavado 300 kg; del CB1 2.500 kg; del CB2 10.300 kg; del CB3 5.500 kg; el resto es de algunos niveles mezclados, en los que puede haber sedimento de la parte superior de un nivel y sedimento de la parte inferior del siguiente nivel superpuesto, o mezcla de varios: de $\mathrm{CB} 1+\mathrm{CB} 290 \mathrm{~kg}$; de CB2+CB3 $240 \mathrm{~kg}$; de CB2+CB1+P $70 \mathrm{~kg}$. En el Sector Oeste, de la campaña de excavación de 1992 en la que participaba E. Moissenet, se lavaron unos $4.000 \mathrm{~kg}$ : la mayor parte, unos $3.300 \mathrm{~kg}$, corresponden al nivel 16 y los restantes $700 \mathrm{~kg}$ a los niveles $17 / 18 / 19$. Todos los niveles mencionados son fosilíferos excepto el nivel $\mathrm{P}$, que no se ha tenido en cuenta en el estudio sistemático porque prácticamente es estéril ya que solo se han encontrado dos fragmentos de dientes de micromamíferos: un fragmento de incisivo superior y un fragmento de un premolar deciduo de un lepórido indeterminado.

Todos los taxones de micromamíferos identificados en el yacimiento que tienen representantes actualmente se han comparado con material actual de los mismos de las colecciones del Museo Nacional de Ciencias Naturales (MNCN). Los dientes se han medido utilizando una lupa que lleva incorporada un micrómetro de $0,025 \mathrm{~mm}$ de precisión. Las medidas se han 
tomado en la superficie oclusal de los dientes orientados en su correspondiente posición anatómica, se expresan en milímetros y corresponden a la longitud (L) y anchura (A) máximas. Se da también la variabilidad de las dimensiones de la talla para cada rango de molar con los valores máximos (Máx.), medios (Med.) y mínimos (Mín.). Cuando en un taxón hay suficientes dientes de un rango en buen estado de conservación, no se han tenido en cuenta las medidas de los dientes muy desgastados para no falsear el resultado total. Cuando se dispone de dientes de un rango del que prácticamente casi todos o la mayoría de los ejemplares están desgastados o muy desgastados (como es el caso del cricétido, en el que los dos únicos $\mathrm{M}_{1}$ que están completos están desgastados, y el de Microtus (I.) brecciensis, en el que de los 12 $\mathrm{M}_{1}$ completos que se han podido medir, 6 están desgastados en mayor o menor grado), se dan las medidas entre paréntesis (en el caso de esta última especie, cuando las medidas extremas: máximas y/o mínimas, no entran dentro de la variabilidad normal de la talla del resto de los molares bien conservados, también se incluyen entre paréntesis) para indicar que son solo aproximadas, en cuyo caso también se dan entre paréntesis los valores medios. El estudio morfológico y biométrico en los arvicolinos se ha realizado sobre el $\mathrm{M}_{1}$ que es la pieza dentaria que permite su identificación, y en los demás taxones sobre todas las piezas mandibulares y dentales que han permitido su clasificación. La nomenclatura utilizada para el estudio de los dientes es la de López Martínez (1980). Los dientes se han dibujado empleando una cámara clara acoplada a una lupa binocular con 40 aumentos y posteriormente se les ha aplicado un tratamiento informático utilizando el programa de dibujo Corel Draw.

Para comparar la abundancia relativa de los diferentes micromamíferos, se ha calculado el NMI (Número Mínimo de Individuos) de cada taxón utilizando de cada grupo la pieza dentaria característica más abundante de las que permiten su identificación, teniendo en cuenta la lateralidad, tomando el número mayor entre derechas e izquierdas. En los arvicolinos el NMI se ha calculado sobre el $\mathrm{M}_{1}$; en los demás taxones se ha tenido en cuenta la pieza dental más abundante de las que han servido para su clasificación.

No se utilizan los términos hemimandíbula o hemimaxilar para abreviar y porque al señalar la lateralidad, derecha (der.) e izquierda (izq.), ya se indica que se trata de una $u$ otra de dichas mitades de la mandíbula o el maxilar superior completos. Otras abreviaturas utilizadas son: mand. (mandíbula), max. sup. (maxilar superior); I (incisivo), D (Diente deciduo), P (Premolar) y M (Molar), con un número en superíndice para los dientes del maxilar superior y con un número en subíndice para los dientes de la mandíbula; fr. (fragmento), N (número de ejemplares), CDLB y CB (Cuesta de la Bajada).

Para la discusión sobre las condiciones ambientales y distribución actual de los diferentes taxones se han utilizado las publicaciones de Blanco (1998), Mitchell-Jones et al. (1999), Palomo \& Gisbert (2002) y Sesé (2005). El registro de los micromamíferos del Cuaternario en España se ha consultado en Sesé (1994), Sesé \& Sevilla (1996) y Arribas (2004), y el de los roedores en Europa en Kowalski (2001).

El material de micromamíferos, una vez estudiado y publicado, quedará finalmente depositado en el Museo Provincial de Teruel.

\section{Paleontología sistemática}

Orden Lagomorpha BRANDT, 1855 - Lagomorfos Familia Leporidae FISCHER, 1817 - Lepóridos Oryctolagus cuniculus (LINNAEUS, 1758) - Conejo (Fig. 2: a y b)

\section{Material por niveles y medidas:}

Hay 8 fr. de mand. con algunos dientes; los demás son dientes aislados. Hay $4 \mathrm{D}_{3}$ y $1 \mathrm{D}^{2}$ de individuos juveniles. Además del número de $\mathrm{P}_{3} \mathrm{y} \mathrm{P}^{2}$ que se da en la Tabla 1, hay numerosos premolares de otro rango y molares: $24 \mathrm{P} / \mathrm{M}$ inf., 13 fr. P/M inf., $23 \mathrm{M}_{3}, 102 \mathrm{P} / \mathrm{M}$ sup., 63 fr. $\mathrm{P} / \mathrm{M}$ sup. y algunos incisivos inf. $\mathrm{y}$ sup. Además de este material dentario, en las excavaciones se recuperaron numerosos restos del esqueleto postcraneal, generalmente huesos largos en su mayoría fragmentados, y piezas del carpo y tarso generalmente completas, algunas vértebras y una pelvis casi completa. Las medidas de los dientes se dan en la Tabla 2.

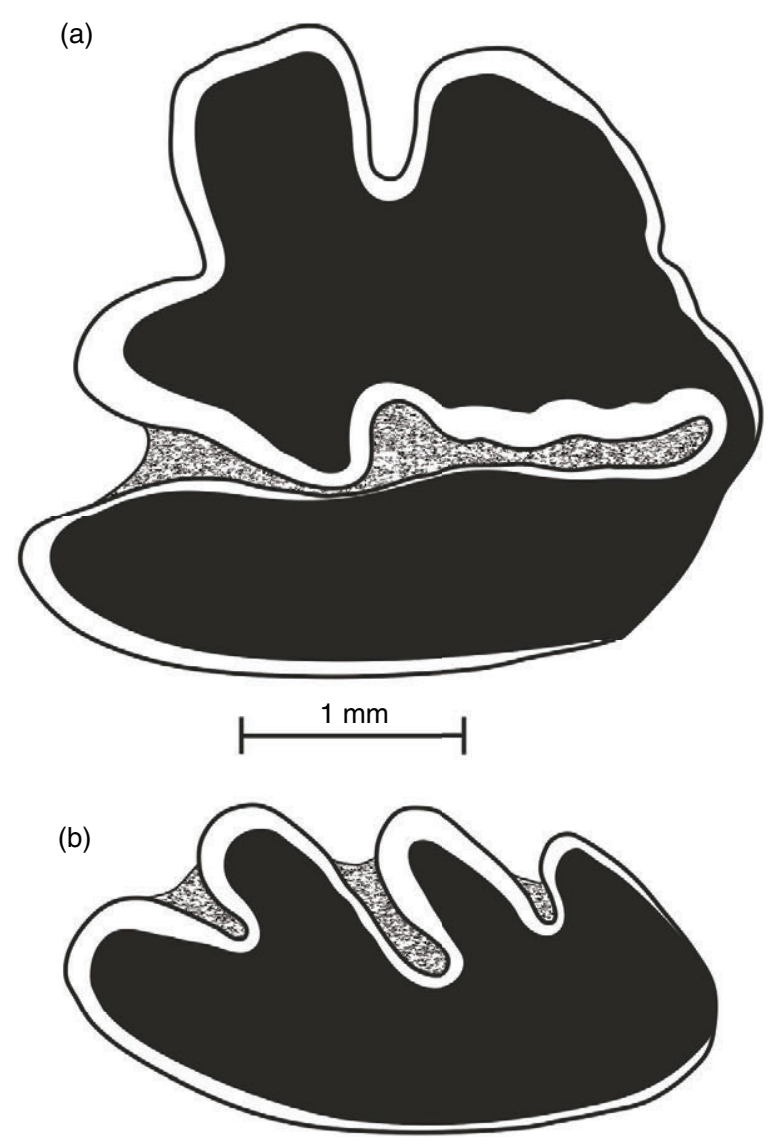

Fig. 2.-Dientes de los lagomorfos de Cuesta de la Bajada en vista oclusal: Oryctolagus cuniculus: a): $\mathrm{P}_{3}$ izq. (CB2; PII AM, 2002: 387); b): $P^{2}$ izq. (CB2; PII, 2002: 7). 
Tabla 1.- Material dentario de Oryctolagus cuniculus de Cuesta de la Bajada por niveles.

\begin{tabular}{lcccccc}
\hline NIVEL & $\mathrm{P}_{3}$ der. & $\mathrm{P}_{3}$ izq. & $\mathrm{P}_{3}$ lado indet. & $\mathrm{P}^{2}$ der. & $\mathrm{P}^{2}$ izq. & NMI \\
\hline CB3 & 14 & 18 & & 10 & 9 & 18 \\
CB3+CB2 & 1 & & & 5 & 7 & 1 \\
CB2 & 10 & 8 & 5 & & 13 \\
CB2+CB1 & & 1 & 5 & 15 & 1 \\
TOTAL NIVELES & 25 & 27 & 53 & 3 \\
\hline
\end{tabular}

Tabla 2.-Medidas de los $\mathbf{P}_{3}$ y $\mathbf{P}^{2}$ de Oryctolagus cuniculus de Cuesta de la Bajada comparadas con las de las poblaciones del Pleistoceno Medio de Cullar de Baza (López Martínez, 1989) y Valdocarros (Sesé et al., 2011a), y del Pleistoceno Superior de PRERESA (Sesé et al., 2011b) y La Peña de Estebanvela (Sesé, 2007).

\begin{tabular}{|c|c|c|c|c|c|c|c|c|c|}
\hline \multirow[b]{2}{*}{ YACIMIENTO } & \multirow[b]{2}{*}{ DIENTE } & \multirow[b]{2}{*}{$\mathrm{N}$} & \multicolumn{3}{|c|}{ LONGITUD } & \multirow[b]{2}{*}{$\mathrm{N}$} & \multicolumn{3}{|c|}{ ANCHURA } \\
\hline & & & MíN. & MED. & MÁX. & & MÍN. & MED. & MÁX. \\
\hline CDLB & $\mathrm{P}_{3}$ & 20 & 1,83 & 2,67 & 3,08 & 20 & 1,73 & 2,65 & 3,27 \\
\hline Cullar de Baza & $\mathrm{P}_{3}$ & 17 & 1,77 & 2,38 & 2,79 & 11 & 1,49 & 2,30 & 2,93 \\
\hline Valdocarros & $\mathrm{P}_{3}$ & 20 & 1,88 & 2,76 & 3,12 & 20 & 1,99 & 2,83 & 3,53 \\
\hline PRERESA & $\mathrm{P}_{3}$ & 44 & 1,85 & 2,82 & 3,48 & 44 & 1,82 & 2,05 & 3,63 \\
\hline Estebanvela & $\mathrm{P}_{3}$ & 127 & 2,11 & 2,79 & 3,22 & 127 & 2,26 & 2,82 & 3,30 \\
\hline CDLB & $P^{2}$ & 11 & 1,12 & 1,18 & 1,64 & 11 & 2,14 & 2,81 & 3,38 \\
\hline Cullar de Baza & $P^{2}$ & 5 & 0,98 & 1,26 & 2,74 & 5 & 2,19 & 2,5 & 2,74 \\
\hline Valdocarros & $P^{2}$ & 8 & 1,18 & 1,46 & 1,61 & 9 & 2,40 & 2,96 & 3,29 \\
\hline PRERESA & $P^{2}$ & 23 & 1,12 & 1,43 & 1,66 & 23 & 2,18 & 2,99 & 3,61 \\
\hline Estebanvela & $\mathrm{P}^{2}$ & 32 & 1,16 & 1,44 & 1,99 & 32 & 2,58 & 2,91 & 3,45 \\
\hline
\end{tabular}

\section{Descripción y discusión:}

La población de Cuesta de la Bajada tiene la talla y la morfología características de Oryctolagus cuniculus: el $\mathrm{P}_{3}$ presenta anterocónidos subiguales, anterofléxido ancho y ortogonal e hipofléxido simple; el $\mathrm{P}^{2}$ tiene postcono y metaflexo bien diferenciados (López Martínez, 1989). La talla (Tabla 2), es algo mayor que la de la población del Pleistoceno Medio de Cullar de Baza (López Martínez, 1989), similar a la del Pleistoceno Medio de Valdocarros (Sesé et al., 2011a), aunque el $\mathrm{P}_{3}$ de este último yacimiento alcanza valores máximos algo mayores, y ligeramente menor que la de los yacimientos del Pleistoceno Superior de PRERESA (Sesé et al., 2011b) y La Peña de Estebanvela (Sesé, 2007).

Uno de los caracteres que distingue a las poblaciones de $O$. lacosti (POMEL, 1853) de los yacimientos pleistocenos de El Carmel y $O$. cf. lacosti de Áridos, Bagur y La Escala, de las de O. cuniculus, según López Martínez (1980 y 1989), es su notable mayor talla. La talla de dichas poblaciones de O. lacosti es mayor también que la de la población de Cuesta de la Bajada.

O. cuniculus se originó en la Península Ibérica, desde dónde se extendió al resto de Europa (López Martínez, 1989 y 2008). Su registro más antiguo es en el yacimiento del primer tercio del Pleistoceno Medio de Cullar de Baza, Granada (López Martínez, 1989). Actualmente tiene una amplia distribución en toda la Península Ibérica aunque es más abundante en la región suroccidental de clima mediterráneo que en la región eurosiberiana septentrional. Las precipitaciones elevadas y las bajas temperaturas parecen ser los factores limitantes de su distribución. Su hábitat ideal es en dehesas con abundante matorral y pastizales (Blanco, 1998; Palomo \& Gisbert, 2002).

Orden Eulipotyphla WADDELL, OKADA \& HASEGAWA, 1999 Familia Soricidae FISCHER, 1814 - Sorícidos

Subfamilia Crocidurinae MILNE-EDWARDS, 1872 - Crocidurinos Crocidura cf. russula (HERMANN, 1780) - Musaraña gris (Fig. 3: 1 y 2)

\section{Material por niveles y medidas:}

- 17/18/19: $1 \mathrm{P}_{4}$ der.; NMI: 1.

- CB3: 1 fr. de mand. der. con I-P $-\mathrm{M}_{1}-\mathrm{M}_{2} ; 1$ fr. de mand. der. con el $\mathrm{M}_{2}$, los alveolos de resto de los molares y parte de la rama ascendente con el cóndilo articular completo; $1 \mathrm{I}^{1}$ izq.; NMI: 2 .

- CB2: $1 \mathrm{M}_{1}$ der.; $1 \mathrm{M}_{2}$ der. en fr. de mand.; $2 \mathrm{I}^{1}$ izq.; 1 fr. $\mathrm{P}^{2-3}$; $1 \mathrm{P}^{4}$ der.; NMI: 2.

Las medidas de los dientes se dan en la Tabla 3.

\section{Descripción y discusión:}

Este material presenta la morfología propia del género Crocidura, fundamentalmente por las siguientes características: las facetas de los cóndilos articulares no están separadas completamente, el borde antero-lingual del incisivo inferior no tiene 

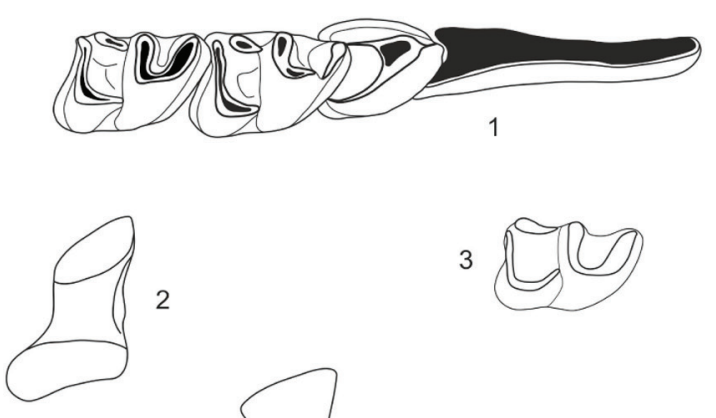

3
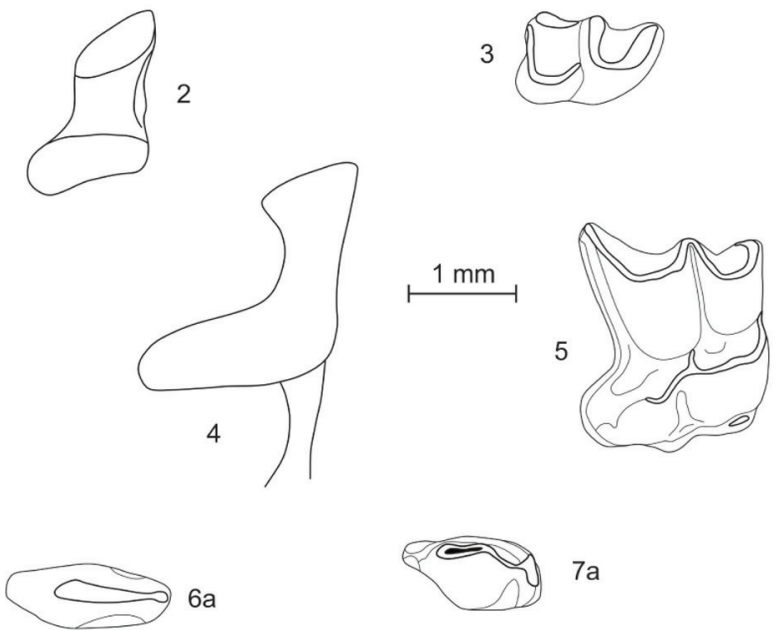

$7 a$
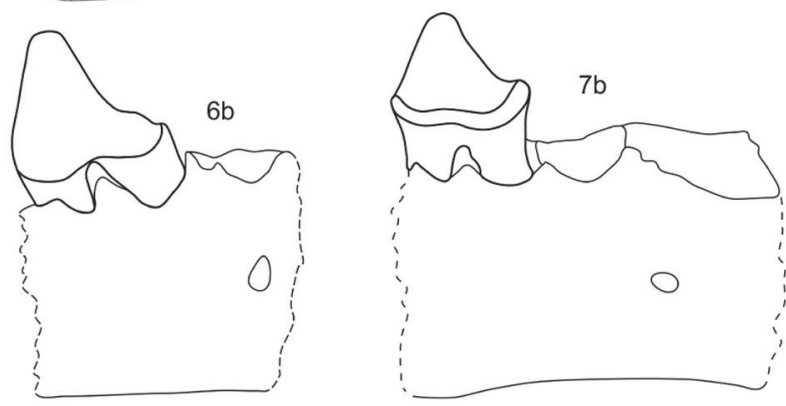

Fig. 3.-Mandíbulas y dientes de los Eulipotyphla de Cuesta de la Bajada: Crocidura cf. russula: 1): Mand. der. con: $1-\mathrm{P}_{4}-\mathrm{M}_{1}-\mathrm{M}_{2}$ en vista oclusal (CB3; PII AM, 2007: 5); 2): Cóndilo articular de mand. der. en vista posterior (CB3; PII AM, 2007: 4); cf. Sorex sp.: 3): $\mathrm{M}_{2}$ der. (16; N. 1: 21); Neomys sp.: 4): Cóndilo articular de mand. der. en vista posterior (CB1; PA, 2002); 5): $\mathrm{M}^{1}$ der. en vista oclusal (CB2; PII, 2002: 10); Talpa sp.: 6): Fr. de mand. izq. con $\mathrm{P}_{1}$ (CB2; PII, 2004: 15): 6a): $\mathrm{P}_{1}$ en vista oclusal; $6 \mathrm{~b}$ ): Mand. y $\mathrm{P}_{1}$ en vista labial; 7): Fr. de mand. izq. con $\mathrm{P}_{4}$ (CB2; PII, 2004: 14): $7 a$ ): $P_{4}$ en vista oclusal; $7 b$ ): Mand. y $P_{4}$ en vista labial. Nota: Ambos fragmentos mandibulares 6 y 7 podrían corresponder al mismo individuo.

crenulaciones y el $\mathrm{P}_{4}$ es de forma tetraédrica sin cuenca posterolingual (Chaline et al., 1974). La morfología del $\mathrm{P}_{4} \mathrm{y}$ del cóndilo articular de la mandíbula, así como la talla, son similares a las de las poblaciones actuales de Crocidura russula. Dada la falta de otras piezas que presenten caracteres con valor diagnóstico, como la serie dentaria inferior completa o la serie premolar superior, realizamos esta atribución con reservas como $C$. cf. russula.

Esta especie se registra en la Península Ibérica desde el Pleistoceno Inferior en el yacimiento de la Sima del Elefante de Atapuerca (Rosas et al., 2006). Actualmente se distribuye ampliamente por toda la Península Ibérica excepto en zonas de gran altitud. Se considera una especie termófila, asociada a un clima y tipo de vegetación mediterráneos, que habita en espacios abiertos y zonas de borde de bosque con buena cobertura vegetal a nivel del suelo (Palomo \& Gisbert, 2002; Sesé, 2005).

Subfamilia Soricinae FISCHER, 1814 - Soricinos

cf. Sorex sp. - Musaraña

(Fig. 3: 3)

Material por niveles y medidas:

- 16: $1 \mathrm{M}_{2}$ der. en fr. de mand.: $\mathrm{L}=1,27$; $\mathrm{A}=0,87$; NMI: 1 .

Descripción y discusión:

Este diente presenta coloreadas las cúspides y crestas a partir de cierta altura, de la misma forma que en las diferentes especies del género Sorex, pero en negro (en lugar de en rojo) con respecto al color ocre del resto del diente, muy posiblemente como resultado de algún proceso durante la fosilización. Su talla es similar a la de las especies actuales Sorex araneus LINNAEUS, 1758 y Sorex coronatus MILLET, 1828. Es el único material en el yacimiento atribuible, aunque con reservas, a este género (de ahí su determinación como cf. Sorex sp.), fundamentalmente por el mencionado carácter que le diferencia de la especie Crocidura cf. russula, presente en el yacimiento. Su pequeña talla le excluye del género Neomys, que también se registra en el yacimiento.

El género Sorex en general requiere suelos húmedos y buena cobertura vegetal de bosque y pradera (Palomo \& Gisbert, 2002).

Neomys sp. - Musgaño

(Fig. 3: 4 y 5)

Material por niveles y medidas:

-CB2: $1 \mathrm{M}^{1}$ der.; 1 fr. de mand. der. con el alveolo del tercer molar y el arranque de la rama ascendente.; 1 fr. de mand. der. con los alveolos de los dos últimos molares y la rama ascendente con el cóndilo articular al que solo le falta el extremo lingual de la faceta inferior; NMI: 2.

-CB1: 1 fr. de mand. der. con el alveolo del tercer molar y fr. de la rama ascendente con el cóndilo articular completo; NMI: 1.

Medidas: $1 \mathrm{M}^{1}: \mathrm{L}=1,82 ; \mathrm{A}=2,17$

\section{Descripción y discusión:}

La morfología del cóndilo articular, con las facetas superior e inferior muy separadas por una área interarticular estrecha y alargada, la faceta superior relativamente corta y la inferior alargada, es la característica del género Neomys. La altura mandibular a nivel del proceso coronoide de $5,12 \mathrm{~mm}$ del fragmento mandibular que conserva completa esta parte, le aproxima a $N$. fodiens (PENNANT, 1771), ya que, según Chaline et al. (1974), en esta especie dicha altura es superior a $4,5 \mathrm{~mm}$, mientras que en $N$. anomalus CABRERA, 1907 es inferior a $4,5 \mathrm{~mm}$. La talla del $\mathrm{M}^{1}$ del yacimiento también es similar a la de $N$. fodiens 
Tabla 3.-Medidas de los dientes de Crocidura cf. russula de Cuesta de la Bajada.

\begin{tabular}{|c|c|c|c|c|c|c|c|c|}
\hline \multirow[b]{2}{*}{ DIENTE } & \multirow[b]{2}{*}{$\mathrm{N}$} & \multicolumn{3}{|c|}{ LONGITUD } & \multirow[b]{2}{*}{$\mathrm{N}$} & \multicolumn{3}{|c|}{ ANCHURA } \\
\hline & & MíN. & MED. & MÁX. & & MíN. & MED. & MÁX. \\
\hline $\mathrm{P}_{4}$ & 2 & 1,09 & 1,23 & 1,38 & 2 & 0,85 & 0,87 & 0,90 \\
\hline $\mathrm{M}_{1}$ & 2 & 1,52 & 1,56 & 1,61 & 2 & 1,05 & 1,08 & 1,11 \\
\hline $\mathrm{M}_{2}$ & 3 & 1,26 & 1,32 & 1,38 & 3 & 0,84 & 0,89 & 0,98 \\
\hline$P^{4}$ & 1 & ----- & $(1,35)$ & ----- & 1 & ----- & $(1,47)$ & ----- \\
\hline
\end{tabular}

actual, y mayor que la de $N$. anomalus actual. No obstante, dada la escasez de material se determina como Neomys sp. al no haber piezas con caracteres diagnóstico que permitan incluirlo con seguridad en una u otra especie.

En Europa ambas especies se registran desde el Pleistoceno Medio (Arribas, 2004). N. fodiens se distribuye actualmente en el tercio norte de la Península Ibérica, mientras que $N$. anomalus tiene una distribución más amplia, especialmente en la mitad septentrional pero también en la mitad oriental de Andalucía, norte de Huelva y sur de Badajoz y Albacete. Ambas especies son semiacuáticas. Aunque pueden vivir alejadas de los cursos de agua, están ligadas a biotopos húmedos (Palomo \& Gisbert, 2002).

\section{Soricidae indet.}

Material por niveles:

-CB2: 1 fr. de mand. izq. con los alveolos del segundo y tercer molar; NMI: 1.

-CB1: 1 fr. de mand. der. con los alveolos del segundo y tercer molar; NMI: 1.

\section{Descripción y discusión:}

La talla de estas piezas entra dentro de la de los géneros Crocidura y Sorex, presentes en el yacimiento, pero no presentan caracteres diagnósticos como para incluirlos en uno $\mathrm{u}$ otro género. En cualquier caso, se puede decir que los Eulipotyphla de menor talla, en general, están algo más representados que lo que indica el material que ha podido ser asignado a dichos géneros respectivamente.

Familia Talpidae FISCHER, 1814 - Tálpidos

Subfamilia Talpinae FISCHER, 1814 - Talpinos

Talpa sp. - Topo

(Fig. 3: 6 y 7)

Material por niveles y medidas:

-CB3: 1 fr. de mand. izq. con los alveolos de molares y premolares; NMI: 1.

-CB2: Hay tres fr. de mand. izq. que parecen corresponder al mismo individuo: $1 \mathrm{fr}$. de mand. izq. con el $\mathrm{P}_{1}$ y los alveolos del segundo premolar; 1 fr. de mand. izq. con el $\mathrm{P}_{4}$ y los alveolos del primer y segundo molar; 1 fr. de mand. izq. con los alveolos del tercer molar y parte de la rama ascendente; NMI: 1.

Medidas: $1 \mathrm{P}_{1}$ : $\mathrm{L}=1,43 ; \mathrm{A}=0,54 ; 1 \mathrm{P}_{4}: \mathrm{L}=1,283 ; \mathrm{A}=0,71$

\section{Descripción y discusión:}

La morfología y la talla de este material es la característica del género Talpa: en la mandíbula con dientes, el $\mathrm{P}_{1}$ es el más notable de los premolares, de aspecto similar al $\mathrm{P}_{4}$ pero de corona algo más alta y menor anchura (Chaline et al., 1974). El material es tan fragmentario que no permite una atribución específica segura.

Las especies actuales del género Talpa presentes en la Península Ibérica, T. europaea LINNAEUS, 1758 y T. occidentalis CABRERA, 1907 requieren suelos blandos, ricos en presas, preferentemente en zonas abiertas de praderas pero también en áreas boscosas (Palomo \& Gisbert, 2002).

Orden Rodentia BOWDICH, 1821 - Roedores

Suborden Sciuromorpha BRANDT, 1855 - Esciuromorfos

Familia Gliridae MUIRHEAD, 1819 - Glíridos

Eliomys quercinus (LINNAEUS, 1766) - Lirón careto

(Fig. 4: 1)

Material y medidas por niveles:

-16: $1 \mathrm{M}^{1}$ der.: $\mathrm{L}=1,45 ; \mathrm{A}=1,95$; NMI: 1 .

\section{Descripción y discusión:}

El molar presenta la morfología característica de Eliomys quercinus. Es más largo pero menos ancho que el único $\mathrm{M}^{1}$ de $E$. quercinus quercinus de Áridos (López Martínez, 1980); entra dentro de la variabilidad de las poblaciones de E. quercinus granatensis de Cueva del Agua (López Martínez \& Ruiz Bustos, 1977) y Solana de Zamborino (García García, 1977), y E. quercinus de La Carigüela (Ruiz Bustos \& García Sánchez, 1977); y es un poco más grande que el de dicha especie de Cullar de Baza I (Ruiz Bustos \& Michaux, 1976) y Pinilla del Valle (Toni \& Molero, 1990).

La presencia de esta especie durante el Pleistoceno se ha asociado a un clima templado con cierto desarrollo forestal (Chaline, 1972). Aunque actualmente vive en muy diversos tipos de hábitats y se considera generalista, se suele encontrar en zonas con cierto desarrollo de la vegetación, bien sea arbustiva o arbórea (Palomo \& Gisbert, 2002; Sesé, 2005).

Suborden Myomorpha BRANDT, 1855 - Miomorfos Superfamilia Muroidea ILLIGER, 1811 - Muroideos Familia Muridae ILLIGER, 1811 - Múridos

Subfamilia Murinae ILLIGER, 1811 - Murinos

Apodemus cf. sylvaticus (LINNAEUS, 1758) - Ratón de campo (Fig. 4: 2 a 4) 

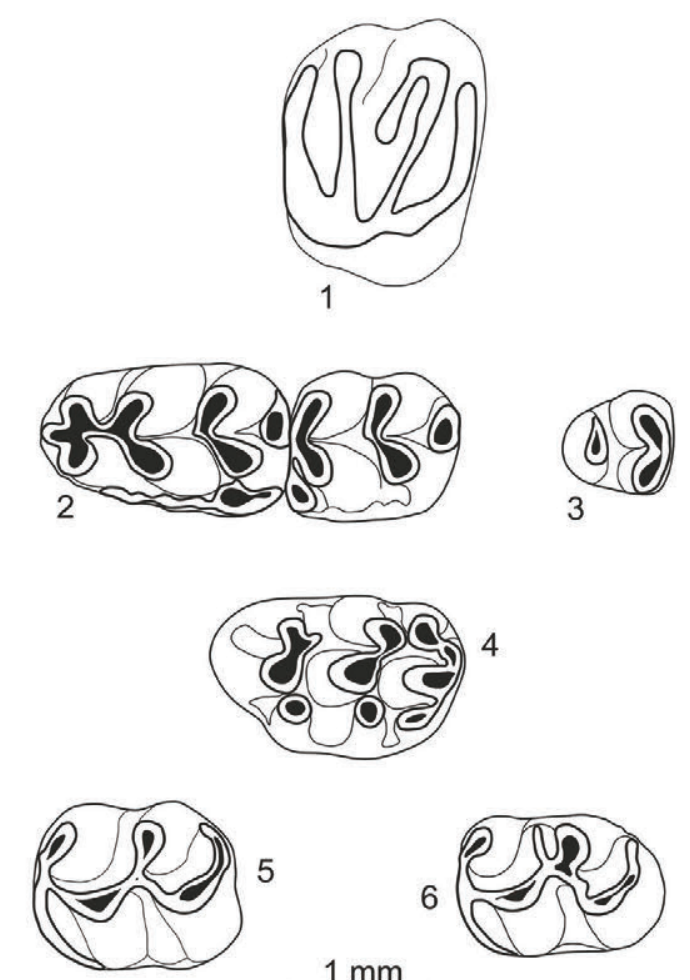

5
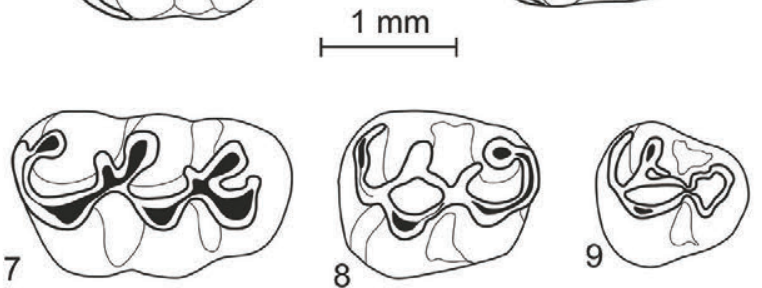

Fig. 4.-Dientes de los roedores de Cuesta de la Bajada en vista oclusal: Eliomys quercinus: 1 ): $\mathrm{M}_{1}$ der. (16; N. 1: 28); Apodemus cf. sylvaticus: 2): $\mathrm{M}_{1}-\mathrm{M}_{2}$ en fr. de mand. izq. (CB3; PII AM, 2007: 2); 3) $M_{3}$ der. (CB2; P II, 2004: 9); 4): $M_{1}$ izq. (CB2; PII, 2004: 8); Cricetulus (A.) bursae: 5): $\mathrm{M}_{2}$ izq. (CB2; PII, 2002: 1); 6): $M_{3}$ izq. (CB3; PII AM, 2007: 1); 7): $M_{1}$ der. (16; AB-N16: 1); 8): $M_{2}$ izq. (CB2; PII, 2000: 25); 9): $M_{3}$ izq. (CB2; PII, 2002: 6).

\section{Material por niveles y medidas:}

-17/18/19: $1 \mathrm{M}_{2}$ der.; NMI: 1.

-16: $1 \mathrm{M}_{1}$ izq.; NMI: 1 .

-CB3: 1 fr. de mand. izq. con $\mathrm{M}_{1}-\mathrm{M}_{2}$; NMI: 1 .

-CB2: $1 \mathrm{M}_{1}$ izq.; $2 \mathrm{M}_{1}$ der.; $1 \mathrm{M}_{3}$ der.; $1 \mathrm{M}^{1}$ izq.; NMI: 2.

-CB1: $1 \mathrm{M}_{1}$ der.; NMI: 1 .

Las medidas de los molares se dan en la Tabla 4.

\section{Descripción y discusión:}

Las medidas de este material entran dentro de la variabilidad de Apodemus cf. sylvaticus de Áridos (López Martínez, 1980), A. sylvaticus de Cullar de Baza I (Ruiz Bustos \& Michaux, 1976) y Apodemus sp. de Valdocarros y PRERESA (Sesé et al.,
2011 a y b), son similares a las de $A$. sylvaticus de Pinilla del Valle (Toni \& Molero, 1990) excepto el $\mathrm{M}^{1}$ que es más grande en este yacimiento, y son más pequeñas que la población de Apodemus cf. sylvaticus de Cueva del Agua (López Martínez \& Ruiz Bustos, 1977). Los molares de las poblaciones actuales de A. flavicollis (MELCHIOR, 1834), según los datos de Pasquier (1974), alcanzan tallas mayores que los de Cuesta de la Bajada. Sin embargo, en ausencia de piezas como el $\mathrm{M}^{2}$ que presenta caracteres con valor diagnóstico que permiten realizar la distinción entre ambas especies (Pasquier, 1974; Michaux \& Pasquier, 1974), realizamos su atribución con reservas como $A$. cf. sylvaticus.

A. sylvaticus actualmente está ampliamente distribuida por toda la Península Ibérica. A. flavicollis es una especie restringida actualmente al tercio norte peninsular con escasa penetración hacia el sur en la Meseta. A. sylvaticus vive generalmente en zonas con una densa vegetación bien sea arbustiva o boscosa, mientras que $A$. flavicollis es estrictamente forestal (Palomo \& Gisbert, 2002). El género Apodemus durante el Pleistoceno se considera en general un indicador termófilo y forestal ya que parece que fue más abundante en los periodos más benignos estando asociado a especies forestales (Michaux \& Pasquier, 1974; Pemán, 1985).

Familia Cricetidae FISCHER, 1817 - Cricétidos Subfamilia Cricetinae FISCHER, 1817 - Cricetinos

Cricetulus (Allocricetus) bursae SCHAUB, 1930 - Hamster migrador

(Fig. 4: 5 a 9)

Material por niveles y medidas:

-17/18/19: 2 M $^{1}$ der.; NMI: 2.

-16: $1 \mathrm{M}_{2}$ izq.; $1 \mathrm{M}^{1}$ der.; $1 \mathrm{M}^{2}$ izq.; NMI: 1 .

-CB3: 1 fr. de mand. izq. con $\mathrm{M}_{1}-\mathrm{M}_{2}-\mathrm{M}_{3} ; 1 \mathrm{M}_{1}$ izq.; 1 fr. de mand. izq. con $\mathrm{M}_{2}-\mathrm{M}_{3} ; 2 \mathrm{M}_{3}$ izq.; NMI: 4.

-CB3+CB2: $3 \mathrm{M}_{2}$ der.; $1 \mathrm{M}^{1}$ izq.; NMI: 3.

-CB2: $1 \mathrm{M}_{1}$ der.; $1 \mathrm{M}_{1}$ izq.; $2 \mathrm{M}_{2}$ izq.; $1 \mathrm{M}_{3}$ der.; $1 \mathrm{M}_{3}$ izq.; 2 $\mathrm{M}^{1}$ izq.; $1 \mathrm{M}^{2}$ der.; $1 \mathrm{M}^{2}$ izq.; 3 fr. $\mathrm{M}^{2}$ lado indet.; $1 \mathrm{M}^{3}$ der.; $1 \mathrm{M}^{3}$ izq.; NMI: 2 .

Las medidas de los molares se dan en la Tabla 5.

\section{Descripción y discusión:}

Gil (1996) describe las poblaciones de Cricetulus (Allocricetus) bursae de varios yacimientos de Atapuerca del Pleistoceno Inferior y Pleistoceno Medio, y concluye que presentan una gran homogeneidad morfológica en todos los niveles y no se observa una tendencia en la talla. Por ello dicho autor (o.c.) señala que no pueden distinguirse ni utilizarse con criterios biostratigráficos las diferentes subespecies cronológicas definidas por Chaline (1971) (A. bursae pyrenaicus en el yacimiento de la Caune de l'Arago), y por Chaline (1972) (A. bursae balaruciensis en Balaruc, A. bursae duranciensis en SaintEstève-Janson, $A$. bursae colombierensis en La Colombière y $A$. bursae correzensis en La Fage), en base a criterios morfológicos principalmente, en yacimientos aislados del Pleistoceno Medio de Francia. 
Tabla 4.-Medidas de los molares de Apodemus cf. sylvaticus de Cuesta de la Bajada.

\begin{tabular}{|c|c|c|c|c|c|c|c|c|}
\hline \multirow[b]{2}{*}{ DIENTE } & \multirow[b]{2}{*}{$\mathrm{N}$} & \multicolumn{3}{|c|}{ LONGITUD } & \multirow[b]{2}{*}{$\mathrm{N}$} & \multicolumn{3}{|c|}{ ANCHURA } \\
\hline & & MíN. & MED. & MÁX. & & MíN. & MED. & MÁX. \\
\hline $\mathrm{M}_{1}$ & 1 & ---- & 1,79 & ---- & 2 & 1,13 & 1,13 & 1,14 \\
\hline$M_{2}$ & 2 & 1,16 & 1,22 & 1,28 & 2 & 1,06 & 1,08 & 1,1 \\
\hline$M_{3}$ & 1 & --- & 0,8 & --- & 1 & --- & 0,78 & ---- \\
\hline$M^{1}$ & 1 & ---- & 1,86 & ---- & 1 & ---- & 1,23 & ---- \\
\hline
\end{tabular}

Tabla 5.-Medidas de los molares de Cricetulus (A.) bursae de Cuesta de la Bajada.

\begin{tabular}{|c|c|c|c|c|c|c|c|c|}
\hline \multirow[b]{2}{*}{ DIENTE } & \multirow[b]{2}{*}{$\mathrm{N}$} & \multicolumn{3}{|c|}{ LONGITUD } & \multirow[b]{2}{*}{$\mathrm{N}$} & \multicolumn{3}{|c|}{ ANCHURA } \\
\hline & & MíN. & MED. & MÁX. & & MíN. & MED. & MÁX. \\
\hline $\mathrm{M}_{1}$ & 2 & $(1,76)$ & $(1,78)$ & $(1,81)$ & 2 & $(1,17)$ & $(1,19)$ & $(1,21)$ \\
\hline $\mathrm{M}_{2}$ & 8 & 1,43 & 1,50 & 1,56 & 8 & 1,22 & 1,25 & 1,29 \\
\hline$M_{3}$ & 3 & 1,35 & 1,41 & 1,51 & 3 & 1,05 & 1,10 & 1,15 \\
\hline$M^{1}$ & 5 & 1,86 & 1,98 & 2,07 & 5 & 1,26 & 1,30 & 1,36 \\
\hline$M^{2}$ & 2 & 1,38 & 1,39 & 1,41 & 3 & 1,20 & 1,22 & 1,24 \\
\hline$M_{3}$ & 2 & 1,13 & 1,13 & 1,13 & 2 & 1,06 & 1,08 & 1,11 \\
\hline
\end{tabular}

A este respecto, estamos de acuerdo con Gil (1996) en que la gran similitud morfológica de las diferentes poblaciones pleistocenas de $C$. (A.) bursae no parece justificar su distinción en diferentes subespecies. Sin embargo, a nuestro juicio, con respecto a la talla, si se comparan poblaciones de la especie de algunos yacimientos del Pleistoceno Medio y Superior de la Península Ibérica con asociaciones faunísticas y/o dataciones numéricas que permiten situarlas biostratigráficamente (Figuras 5 y 6), sí que parece observarse que, aunque no es un tendencia gradual y hay solapamiento de las tallas entre ellas, hay una cierta tendencia al aumento de la talla durante el Pleistoceno, siendo las del Pleistoceno Superior claramente de mayor talla que las del Pleistoceno Medio inicial y avanzando. La talla de la población de esta especie de Cuesta de la Bajada, es mayor que la del yacimiento del Pleistoceno Medio inicial de Cullar de Baza I (Ruiz Bustos \& Michaux, 1976); comparable a la del yacimiento del Pleistoceno Medio típico de Áridos (López Martínez, 1980); algo inferior a la del yacimiento del Pleistoceno Medio avanzado pero no final de Valdocarros (Sesé et al., 2011a); y claramente menor que la de las poblaciones del Pleistoceno Superior de PRERESA (Sesé et al., 2011b) y Pinilla del Valle (Toni \& Molero, 1990). Sin embargo, la variación de la talla de la población de Cuesta de la Bajada está entre las medidas más pequeñas de las poblaciones de la especie de los diferentes niveles de Gran Dolina y Galería de Atapuerca (Gil, 1986 y 1996). Las poblaciones del Pleistoceno Medio de los niveles superiores de TD-10 y TD-11 de Atapuerca son de mayor talla que las del yacimiento de Cuesta de la Bajada. Recientemente el antiguo nivel fosilífero de la base de TD-11 (Rodríguez et al., 2011), se ha recolocado en su verdadera posición estratigráfica que es el techo de TD-10, nivel que está a su vez subdividido en cuatro subniveles con cronologías entre $244 \pm 26$ ka y $458 \pm 47$ ka (Falguères et al., 1999; Berger et al., 2008; Moreno et al., 2015). El yacimiento de Cuesta de la Bajada se situaría por tanto en esa horquilla con edades entre 300.000 y 400.000 años, lo que es coherente con lo expuesto anteriormente.

C. (A.) bursae se registra en la Península Ibérica desde el final del Pleistoceno Inferior, en los niveles inferiores de Gran Dolina (Gil, 1986 y 1996; Sesé \& Gil, 1987; Sesé, 1994; Sesé \& Sevilla, 1996), y durante el Pleistoceno Medio y Pleistoceno Superior en numerosos yacimientos, excepto en la región Pirenaica (Arribas, 2004) y noreste peninsular (López-García, 2008). En la región Cantábrica no se habían encontrado restos de esta especie (Altuna, 1972; Sesé, 2005) hasta recientemente en los yacimientos del Pleistoceno Superior de Lezetxiki (Guipúzcoa) (Rofes et al., 2012; García-Ibaibarriaga et al., 2015) y Arlanpe (Vizcaya) (García-Ibaibarriaga et al., 2013). En todo caso, dados los escasos hallazgos hasta ahora, con pocos restos y solo en dos yacimientos de la Región Cantábrica, en la que sin embargo son tan numerosos los yacimientos del Pleistoceno Superior y Holoceno, parece que este cricétido, un inmigrante en la Península Ibérica procedente de Eurasia, no tuvo en dicha región una gran penetración más allá de la zona oriental próxima a Francia en la que se localizan dichos yacimientos, quizás porque en general no reunía las condiciones de clima y hábitats más favorables para su expansión. Hasta ahora la cita más reciente de esta especie es en el yacimiento del final del Pleistoceno Superior de Cueva Ambrosio, datado entre 17.900 y 16.500 años BP (Sesé \& Soto, 1988; Sesé, 1994; Sesé \& Sevilla, 1996).

Según Kowalski (2001) Cricetulus (Allocricetus) bursae es sinonimia de la especie actual Cricetulus migratorius (PALLAS, 1773) que se distribuye desde Europa del Este hasta China. Actualmente esta última especie, aunque tiene una gran plasticidad en el tipo de hábitats en los que vive, parece preferir en general las áreas abiertas, estepas y pedregales con escasa vegetación, praderas secas y zonas desérticas o semidesérticas (Mitchell-Jones et al., 1999). 

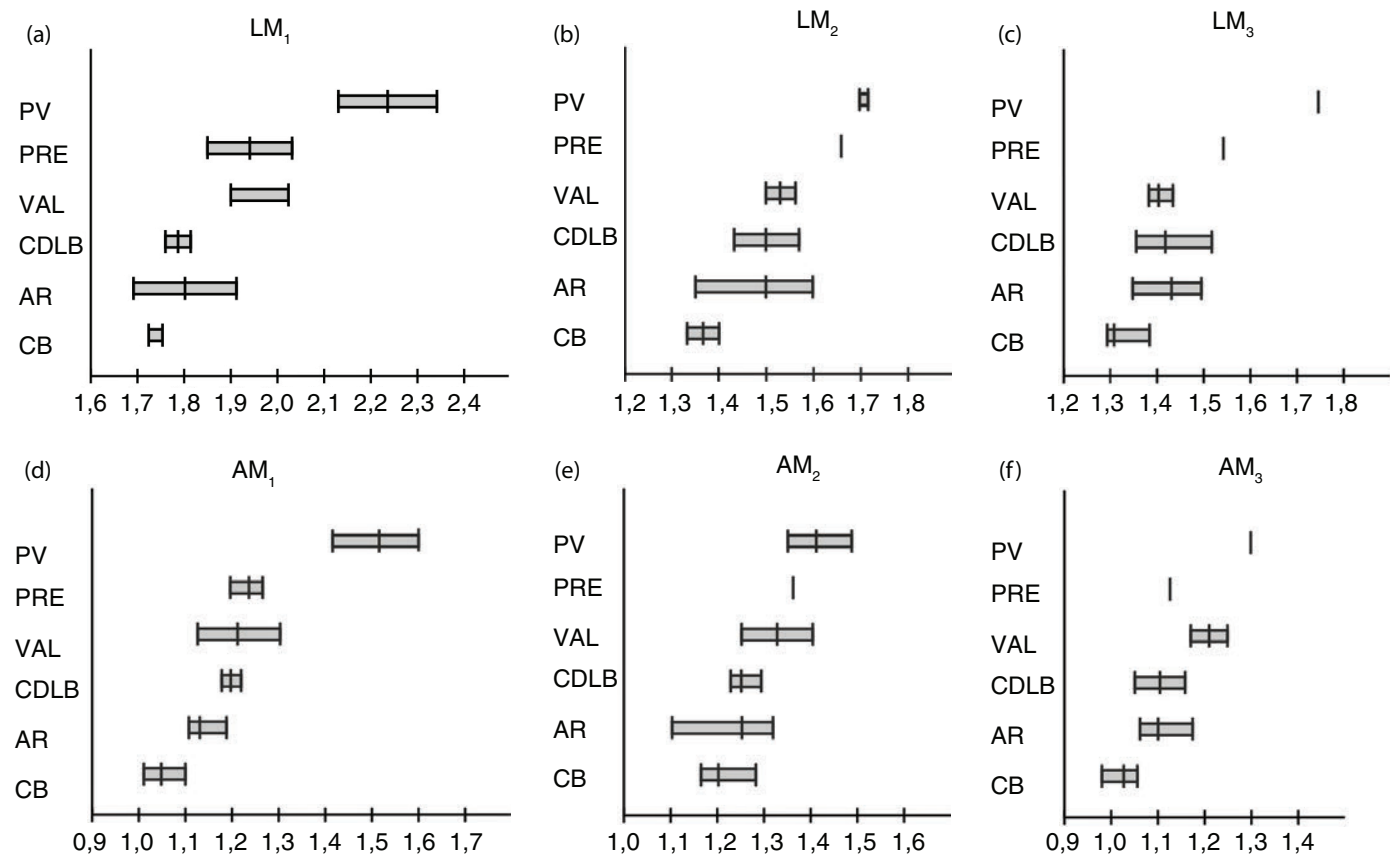

Fig. 5.--Medidas de los molares inferiores de Cricetulus (A.) bursae de diversos yacimientos pleistocenos. Se representa en abscisas la amplitud de variación (valores mínimo y máximo) y el valor medio en milímetros de la longitud ( $L$ ) y anchura $(A)$ de los molares de los yacimientos situados en ordenadas. Los yacimientos representados y el número de ejemplares (N) de los $M_{1}, M_{2}$ y $M_{3}$ respectivamente de cada uno de ellos son: Cullar de Baza (CB), (N: 5-5-5), (Ruiz Bustos \& Michaux, 1976); Áridos (AR), (N: 7-8/7-4), (López Martínez, 1980); Cuesta de la Bajada (CDLB), (N: 2-8-3); Valdocarros (VAL), ( $N=2-4-3 / 2)$ (Sesé et al., 2011a); PRERESA (PRE), (N: 2-1-1), (Sesé et al., 2011b); Pinilla del Valle (PV), (N: 2-2/3-1), (Toni \& Molero, 1990).

Subfamilia Arvicolinae GRAY, 1821 - Arvicolinos Arvicola aff. sapidus MILLER, 1908 - Rata de agua (Fig. 7: 1)

\section{Material por niveles y medidas:}

Hay 4 fr. mandibulares con $\mathrm{M}_{1}-\mathrm{M}_{2}$; los demás son dientes aislados.

-CB3: $1 \mathrm{M}_{1}$ der.; $1 \mathrm{M}_{1}$ izq.; NMI: 1 .

-CB2: $5 \mathrm{M}_{1}$ der.; $3 \mathrm{M}_{1}$ izq.; NMI: 5 .

$-\mathrm{CB} 2+\mathrm{CB} 1+\mathrm{P}: 1 \mathrm{M}_{1}$ der.; NMI: 1 .

Las medidas de los $\mathrm{M}_{1}$ se dan en la Tabla 6.

\section{Descripción y discusión:}

En los $\mathrm{M}_{1}$ en los que el esmalte está diferenciado, la diferenciación es negativa, es decir, el esmalte de la parte posterior de los triángulos es más grueso que el de la parte anterior, como sucede en Arvicola sapidus, lo que le diferencia de Arvicola terrestris (LINNAEUS, 1758) (especie denominada también Arvicola amphibius (LINNAEUS, 1758) por algunos autores), en la que, por el contrario, el esmalte presenta una diferenciación positiva, es decir que el esmalte de la parte posterior de los triángulos es más fina que la anterior.

La diferenciación del esmalte negativa que presenta $A$. sapi$d u s$, es, no obstante, un carácter compartido con otras especies pleistocenas extintas, como A. jacobaeus CUENCA-BESCÓS,
AGUSTI, LIRA, MELERO RUBIO \& ROFES, 2010, definida en el yacimiento del Pleistoceno Inferior de la Unidad Inferior Roja de la Sima del Elefante de Atapuerca (Cuenca-Bescós et al., 2010), y A. cantianus (HINTON, 1910) del Pleistoceno Medio que en la literatura científica se encuentra generalmente bajo la denominación de $A$. cantiana. Algunos autores consideran $A$. mosbachensis (SCHMINDTGEN, 1911) sinonimia de $A$. cantiana. Sin embargo, otros autores utilizan A. mosbachensis siguiendo el criterio de Maul et al. (2000) que la redefinieron en el yacimiento tipo de Mosbach con un material representativo, proponiendo utilizarla para las poblaciones europeas del Pleistoceno Medio, reservando la denominación de $A$. cantiana exclusivamente para el escaso y fragmentario material tipo por el que fue definido esta última. Debido a la gran similitud morfológica entre A. jacobaeus, A. mosbachensis y A. sapidus por una parte, y sus diferencias morfológicas con $A$. terrestris por otra, Martin (2015) plantea la siguiente hipótesis sobre la evolución del género Arvicola en el oeste de Europa: los primeros representantes del género Arvicola (A. jacobaeus) son las primeras poblaciones de Arvicola sapidus, especie a la que pertenecen todas las poblaciones posteriores en las que es predominante la diferenciación negativa del esmalte en dientes inferiores; las poblaciones en las que predomina la diferenciación positiva del esmalte serían $A$. terrestris; y las poblaciones pleistocenas intermedias representarían el proceso de especiación en curso de $A$. terrestris a partir de $A$. sapidus. 

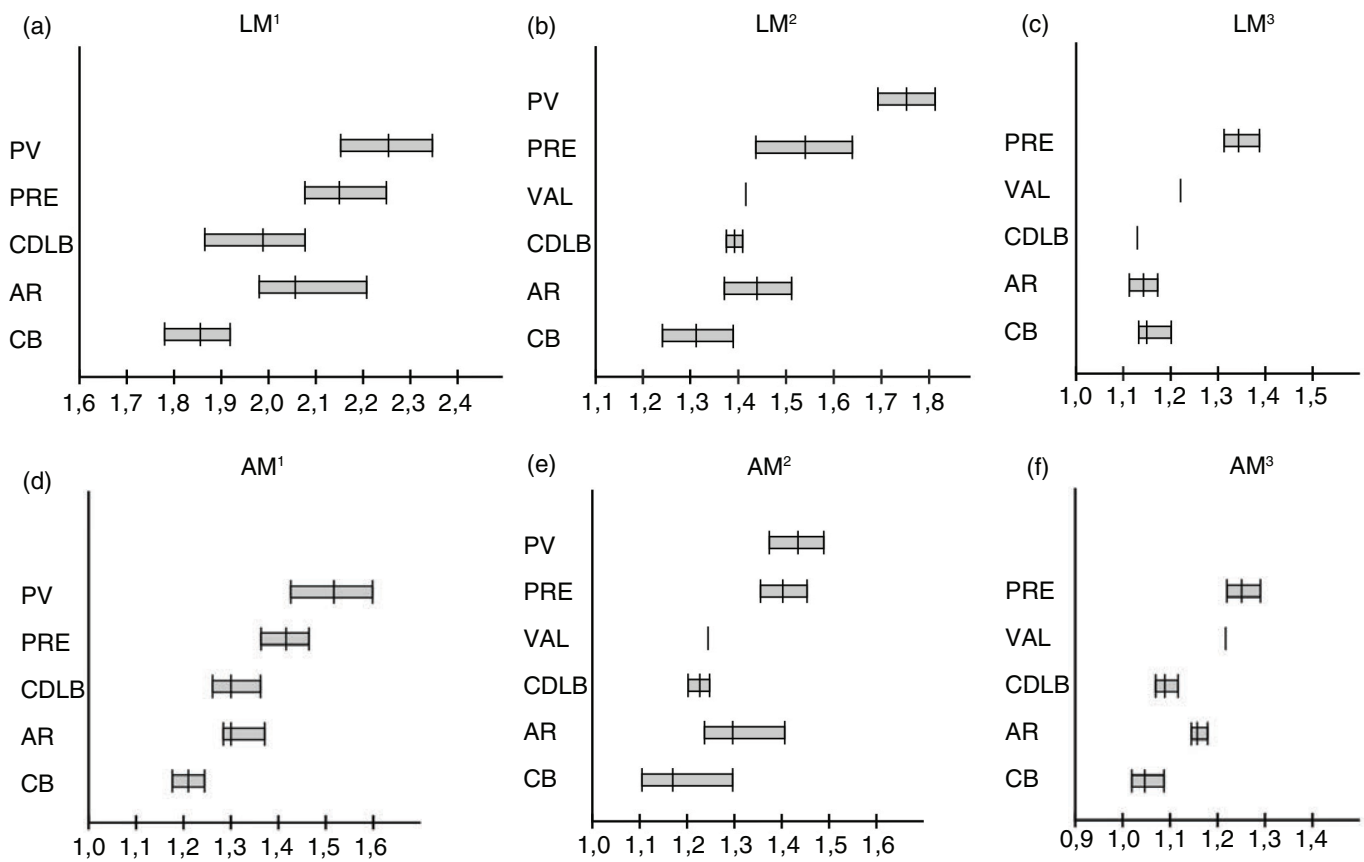

Fig. 6.-Medidas de los molares superiores de Cricetulus (A.) bursae de diversos yacimientos pleistocenos. Se representa en abscisas la amplitud de variación (valores mínimo y máximo) y el valor medio en milímetros de la longitud (L) y anchura (A) de los molares de los yacimientos situados en ordenadas. Los yacimientos representados y el número de ejemplares (N) de los $M^{1}, M^{2}$ y $M^{3}$ respectivamente de cada uno de ellos son: Cullar de Baza I (CB), (N: 8-8-4), (Ruiz Bustos \& Michaux, 1976); Áridos (AR), (N: 5-6-3), (López Martínez, 1980); Cuesta de la Bajada (CDLB), (N: 5-2/3-2); Valdocarros (VAL), ( $=0$-1-1) (Sesé et al., 2011a); PRERESA (PRE), (N: 6-5-3), (Sesé et al., 2011b); Pinilla del Valle (PV), (N: 2-2/3-0), (Toni \& Molero, 1990).

En lo referente a la longitud de los $\mathrm{M}_{1}\left(\mathrm{~L} \mathrm{M}_{1}\right)$ de Cuesta de la Bajada, se pueden realizar las siguientes observaciones sobre la Figura 8: A. jacobaeus de la Sima del Elefante de Atapuerca (Cuenca-Bescós et al., 2010), tiene una talla mínima que es la más pequeña conocida para una especie del género Arvicola, un poco por debajo de la de A. mosbachensis de Cullar de Baza I (Ruiz Bustos \& Michaux, 1976), aunque los valores medios y máximos son similares a los de ésta; la población de Cuesta de la Bajada prácticamente encaja entre el valor medio y un poco más del máximo de la de Atapuerca. La talla $\left(\mathrm{L} \mathrm{M}_{1}\right)$ de Cuesta de la Bajada es solo algo mayor que la de A. mosbachensis de Cullar de Baza I (Ruiz Bustos \& Michaux, 1976), entra dentro de la variabilidad de la de $A$. aff. sapidus de Áridos (López Martínez, 1980), tiene valores algo menores que las de $A$. aff. sapidus de PRERESA (Sesé et al., 2011b) y $A$. cf. sapidus de Cueva del Agua (López Martínez \& Ruiz Bustos, 1977), es menor que la de A. sapidus de Pinilla del Valle (Toni \& Melero, 1990) y La Carigüela (Ruiz Bustos \& García Sánchez, 1977) y Arvicola aff. sapidus de TG-11 de Atapuerca (Gil, 1986), y es claramente menor que la de $A$. cf. sapidus de Solana de Zamborino (García García, 1977). Finalmente, todas las poblaciones pleistocenas mencionadas son de menor talla que A. sapidus actual (López Martínez, 1980; Sesé et al., 2011 a y b), razón por la que estos y otros autores las denominan A. aff. sapidus/A. cf. sapidus. Parece, por tanto que, aunque quizás no es una tendencia gradual, y hay una gran variación y solapamiento entre las tallas, en general se puede decir que las poblaciones de $A$. sapidus del Pleistoceno Superior son de mayor talla que las del Pleistoceno Medio y Pleistoceno Inferior, y que todas ellas son de menor talla que las de las poblaciones actuales de la especie.

A. sapidus es una especie endémica del sudoeste de Europa que actualmente solo se distribuye en la Península Ibérica y Francia. Es típicamente ripícola o semiacuática: vive ligada a riberas de cursos de agua constantes de baja energía con abundante vegetación ribereña de la que se alimenta, aunque a veces también se encuentra lejos del agua en praderas húmedas (López Martínez, 1980; Mitchell-Jones et al., 1999; Palomo \& Gisbert, 2002).

Microtus (Iberomys) brecciensis (GIEBEL, 1847) - Topillo de la brechas

(Fig. 7: 2 a 8)

\section{Material por niveles y medidas:}

Hay 5 fr. de mand. con el $\mathrm{M}_{1}$ (dos de ellas también con el $\mathrm{M}_{2}$ ); los demás son dientes aislados.

-CB3: $6 \mathrm{M}_{1}$ der.; $8 \mathrm{M}_{1}$ izq.; NMI: 8 .

-CB3+CB2: 3 M 1 der.; NMI: 3 .

-CB2: $4 \mathrm{M}_{1}$ der.; $7 \mathrm{M}_{1}$ izq.; NMI: 7.

$-\mathrm{CB} 2+\mathrm{CB} 1+\mathrm{P}: 1 \mathrm{M}_{1}$ izq.; NMI: 1 .

-CB1: $2 \mathrm{M}_{1}$ der.; $2 \mathrm{M}_{1}$ izq.; NMI: 2.

Las medidas de los $\mathrm{M}_{1}$ se dan en la Tabla 7. 

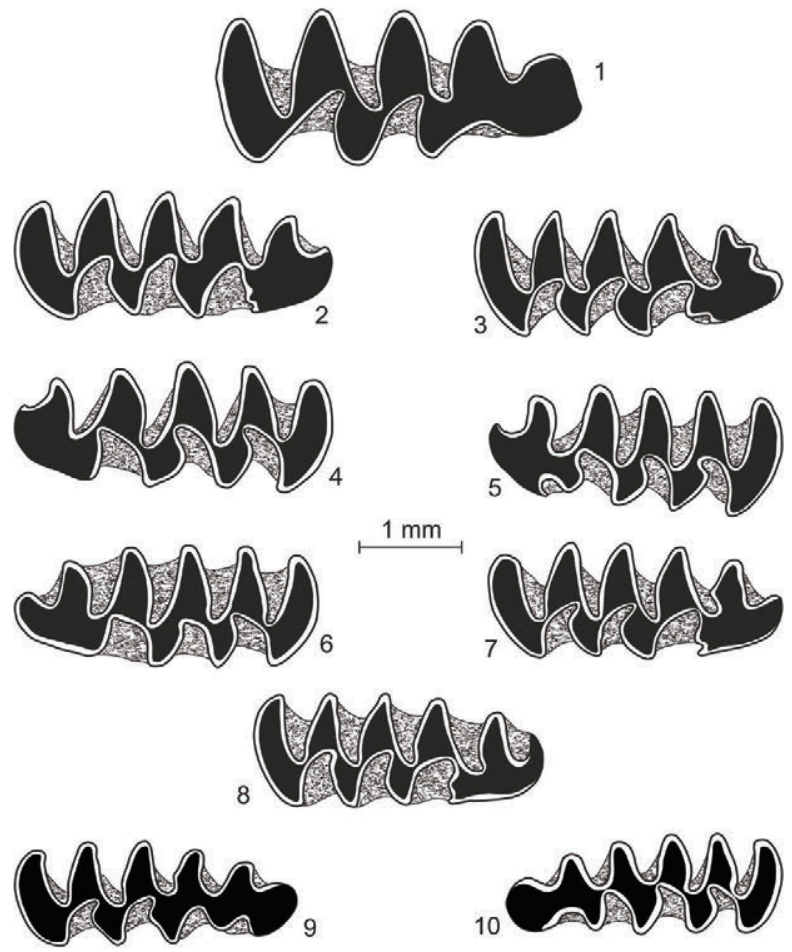

Fig. 7.-Dientes de los roedores de Cuesta de la Bajada en vista oclusal: Arvicola aff. sapidus: 1): $\mathrm{M}_{1}$ der. (CB2; PII, 2002: 1); Microtus (I.) brecciensis: 2): $\mathrm{M}_{1}$ der. (CB2; PII, 2002: 30); 3): $M_{1}$ der. (CB3+CB2; PII + AM, 1999: 3); 4): $M_{1}$ izq. (CB3; PII AM, 2007: 25); 5): $M_{1}$ izq. (CB3; PII AM, 2007: 23); 6): $M_{1}$ izq. (CB2; PII, 2007); 7): $\mathrm{M}_{1}$ der. (CB2; PII, 2002: 32); 8): $\mathrm{M}_{1}$ der. (CB3+CB2; PII + AM, 1999: 4); Microtus (T.) duodecimcostatus: 9): $\mathrm{M}_{1}$ der. (CB2; PII, 2002: 6); 10): $\mathrm{M}_{1}$ izq. (CB2; PII, 2002: 11).

\section{Descripción:}

El $\mathrm{M}_{1}$ en vista oclusal consta de lóbulo posterior, cinco triángulos cerrados y complejo anterocónido asimétrico. La variabilidad de la morfología del $\mathrm{M}_{1}$ de Microtus (I.) brecciensis y de su descendiente, Microtus (I.) cabrerae THOMAS, 1906, se presenta en el complejo anterocónido (Ayarzaguena \& López Martínez, 1976; López Martínez, 1980; Cabrera-Millet et al., 1982). Con respecto a los 10 morfotipos de la población de $M$. (I.) brecciensis del yacimiento de Áridos que distingue López Martínez (1980: Fig. 10: A; p. 171), el reparto del número de ejemplares y porcentaje de los mismos de la población de Cuesta de la Bajada es el que se muestra en la Tabla 8.

Los morfotipos $\mathrm{n}^{\mathrm{o}} 1$ y 2 , con anterocónido irregular y poco desarrollado, corresponden a individuos juveniles; los $\mathrm{n}^{\mathrm{o}} 3,4$

Tabla 6.-Medidas de los $\mathbf{M}_{1}$ de Arvicola aff. sapidus de Cuesta de la Bajada.

\begin{tabular}{|c|c|c|c|c|c|c|c|c|}
\hline \multirow[b]{2}{*}{ DIENTE } & \multirow[b]{2}{*}{$\mathrm{N}$} & \multicolumn{3}{|c|}{ LONGITUD } & \multirow[b]{2}{*}{$\mathrm{N}$} & \multicolumn{3}{|c|}{ ANCHURA } \\
\hline & & MíN. & MED. & MÁX. & & MíN. & MED. & MÁX. \\
\hline $\mathrm{M}_{1}$ & 9 & 3,47 & 3,68 & 3,98 & 7 & 1,5 & 1,56 & 1,76 \\
\hline
\end{tabular}

y 5 presentan los ángulos LRA 4 y BRA 3 casi enfrentados y la cúspide anterior más simétrica de tipo Allophaiomys en el $n^{\circ}$ 3 y de tipo "arvaloide" en los $n^{\circ} 4$ y 5 ; en los morfotipos del no 6 al 10 los ángulos LRA 4 y BRA 3 son alternos y el anterocónido es muy asimétrico, tipo "nivaloide", muy característico de Microtus (I.) brecciensis (López Martínez, 1980). Como se observa en la Tabla 8, en la población de Cuesta de la Bajada, como sucede en la población de Áridos, los morfotipos más frecuentes son $\operatorname{los} \mathrm{n}^{\mathrm{o}} 6$ y 7 , con porcentajes muy altos y bastante similares en ambos yacimientos. Según López Martínez (1980) en Cullar de Baza los morfotipos n ${ }^{\circ} 6$ y 7 son también los más frecuentes, y el morfotipo $\mathrm{n}^{\mathrm{O}} 4$ (que no se encuentra en Cuesta de la Bajada) se presenta en el $25 \%$ de la población; mientras que en la Cueva del Agua es también frecuente el morfotipo $n^{\circ} 8$ que se da en el $10 \%$ de la población, mientras que en Áridos es del $5,45 \%$ y en Cuesta de la Bajada es del 6,9\%. Es decir que, por morfología, la población de Cuesta de la Bajada tiene un estadio evolutivo bastante similar al del yacimiento de Áridos.

En el estudio llevado a cabo por Gil (1997) sobre las diferentes poblaciones de $M$. (I.) brecciensis de los yacimientos de Gran Dolina y Complejo de Tres Simas de Atapuerca, teniendo en cuenta la variación de la longitud del $\mathrm{M}_{1}\left(\mathrm{~L} \mathrm{M}_{1}\right)$, dicho autor pone de manifiesto una tendencia hacia el aumento de la talla. Recientemente Laplana \& Sevilla (2013) comparan la longitud del $\mathrm{M}_{1}$ de las poblaciones de Iberomys mejor representadas de los yacimientos del Pleistoceno y Holoceno, y M. (I.) cabrerae actual de la Península Ibérica, y observan asimismo la tendencia al aumento de la misma, señalando que esta última especie es notablemente de mayor talla que su posible antecesor $M$. (I.) brecciensis. En efecto, en la Figura 9 en la que se ha representado la $\mathrm{L} \mathrm{M}_{1}$ de la diversas poblaciones de yacimientos que tienen dataciones numéricas del Pleistoceno Inferior y Medio de M. (I.) brecciensis, y M. (I.) cabrerae del Pleistoceno Superior y actual, se observa también dicha tendencia: las poblaciones de M. (I.) brecciensis del Pleistoceno Inferior, en general, tienen unas amplitudes de variación de la talla algo menores que las del Pleistoceno Medio y estas a su vez son algo inferiores a las de $M$. (I.) cabrerae del Pleistoceno Superior y actual. En este sentido, con respecto a la variación de la talla $\left(\mathrm{L} \mathrm{M}_{1}\right)$ de la población de M. (I.) brecciensis de Cuesta de la Bajada se pueden realizar las siguientes precisiones: es algo mayor que la de dicha especie del Pleistoceno Inferior de los yacimientos de Gran Dolina (Gil, 1986 y 1997) y Huéscar 1 (Mazo et al., 1985); encaja en la de los yacimientos de Cullar de Baza I (Ruiz Bustos \& Michaux, 1976) y Áridos (López Martínez, 1980); mientras que M. (I.) brecciensis de Valdocarros (Sesé et al., 2011a) y M. (I.) cabrerae de los yacimientos de PRERESA (Sesé et al., 2011b) y Pinilla del Valle (según Toni \& Molero, 1990; identificada por estos autores como $M$. (I.) brecciensis pero posteriormente determinada como M. (I.) cabrerae por Laplana \& Sevilla, 2006), tienen una amplitud de variación algo mayor, y, finalmente, la talla de la población actual de esta última especie es claramente mayor. Paunesco \& Brunet-Lecomte (2005) también señalan la diferencia de talla de la longitud del $\mathrm{M}_{1}$ entre $M$. (I.) brecciensis y $M$. (I.) cabrerae, más grande en esta última especie que en la primera. Laplana \& Sevilla (2013) indican que la media de la longitud del $\mathrm{M}_{1}$ de $M$. (I.) brecciensis del Pleistoceno Medio no 


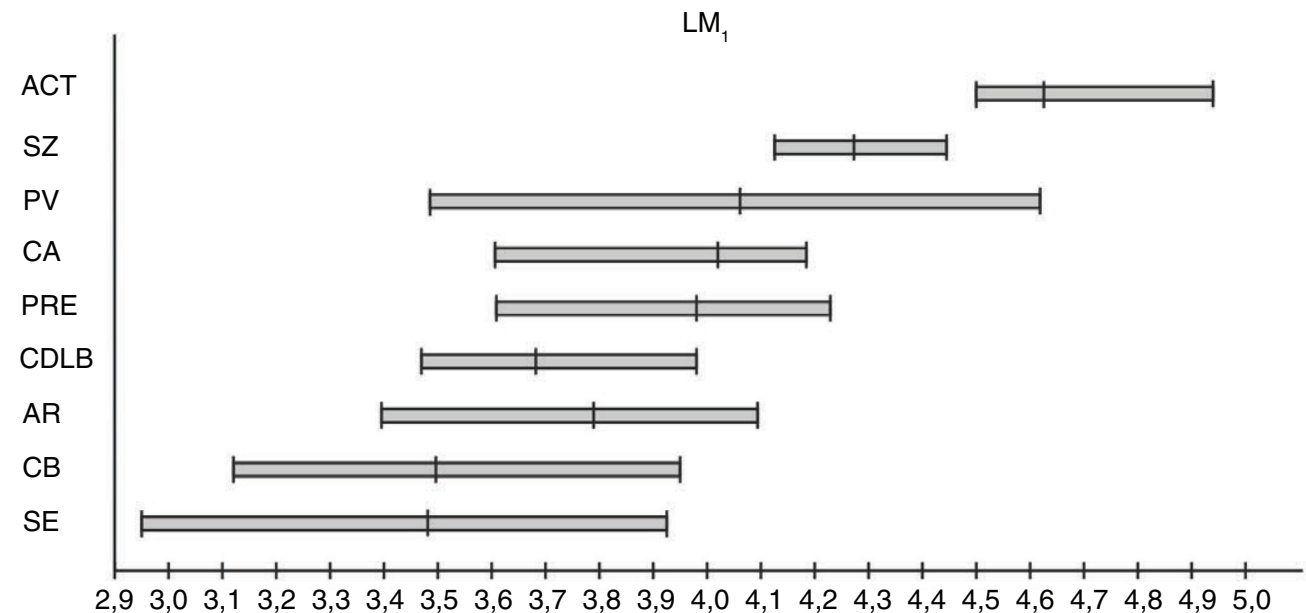

Fig. 8.-Medidas del $\mathrm{M}_{1}$ de varias especies del género Arvicola de diversos yacimientos pleistocenos y localidades actuales. Se representa en abscisas la amplitud de variación (valores mínimo y máximo) y el valor medio en milímetros de la longitud $(L)$ de los $M_{1}$ de las localidades situadas en ordenadas. Las especies, yacimientos y localidades representadas, y el número de ejemplares (N) de cada una de ellas son: A. jacobaeus de la Unidad Inferior Roja de la Sima del Elefante de Atapuerca (SE), (N: 44), (Cuenca-Bescós et al., 2010); A. mosbachensis de Cullar de Baza I (CB), (N: 13), (Ruiz Bustos \& Michaux, 1976); A. aff. sapidus de: Áridos (AR), (N: 8), (López Martínez, 1980); Cuesta de la Bajada (CDLB), (N: 9); PRERESA (PRE), (N: 12), (Sesé et al., 2011b); A. cf. sapidus de Cueva del Agua (CA), (N: 5), (López Martínez \& Ruiz Bustos, 1977); A. sapidus de Pinilla del Valle (PV), (N: 19), (Toni \& Molero, 1990); A. cf. sapidus de Solana de Zamborino (SZ), (N: 4), (García García, 1977); A. sapidus actual del sur de España (ACT), (N: 12), (Sesé et al., 2011b).

Tabla 7.-Medidas de los $\mathbf{M}_{1}$ de Microtus (I.) brecciensis de Cuesta de la Bajada.

\begin{tabular}{|c|c|c|c|c|c|c|c|c|}
\hline \multirow[b]{2}{*}{ DIENTE } & \multirow[b]{2}{*}{$\mathrm{N}$} & \multicolumn{3}{|c|}{ LONGITUD } & \multirow[b]{2}{*}{$\mathrm{N}$} & \multicolumn{3}{|c|}{ ANCHURA } \\
\hline & & MÍN. & MED. & MÁX. & & MÍN. & MED. & MÁX. \\
\hline$M_{1}$ & 12 & 2,65 & $(2,91)$ & $(3,10)$ & 11 & $(1,09)$ & $(1,21)$ & $(1,32)$ \\
\hline
\end{tabular}

excede los 2,95 mm, y la de $M$. (I.) cabrerae está siempre por encima de 3,04 mm en el Pleistoceno Superior y Holoceno, algo que sucede en la representación de las medidas de la mencionada Figura 9. De todas formas, en nuestra opinión, las cifras que dan estos últimos autores (o.c.) no deberían utilizarse como un patrón exacto de clasificación de una población en una u otra especie, sino con cautela ya que esa medida depende de diversos factores. Así por ejemplo, no es lo mismo disponer de una población numerosa en la que la variabilidad puede estar suficientemente bien representada, que disponer de escasos ejemplares y utilizar dicha medida como una cifra de corte para clasificar esos ejemplares en una u otra especie. A nuestro juicio hay que tener también en consideración el intervalo de variación total de las medidas, y no sólo el valor medio, debido al amplio solapamiento que existe de esta variabilidad entre las distintas poblaciones de Iberomys. Así mismo, para clasificar las poblaciones en una u otra especie, es muy importante tener en cuenta la morfología que, tal como señalaron distintos autores (Ayarzaguena \& López Martínez, 1976; López Martínez, 1980; Cabrera-Millet et al., 1982; Paunesco \& Brunet-Lecomte, 2005), presenta a lo largo del tiempo la modificación de la parte anterior del complejo anterocónido del $\mathrm{M}_{1}$, más compleja y modificada en $M$. (I.) cabrerae con respecto a $M$. (I.) brecciensis.

\section{Discusión:}

Iberomys fue definido inicialmente por Chaline (1972) como subgénero del género Microtus, en el que incluyó las especies Microtus (I.) brecciensis y Microtus (I.) dentatus MILLER, 1910 por ciertas características morfológicas compartidas que les diferencian de otros subgéneros de Microtus. M. (I.) dentatus fue considerada sinonimia de M. (I.) cabrerae THOMAS, 1906 por Niethammer et al. (1964), Ayarzaguena \& López Martínez (1976) y Cabrera Millet et al. (1982), denominación que tiene prioridad.

Posteriormente se incluyó en Iberomys la especie Pitymys huescarensis RUIZ BUSTOS, 1988, definida por Ruiz Bustos (1988) sobre parte del material atribuido al género Microtus en el yacimiento de Huéscar 1, que inicialmente Mazo et al. (1985) determinaron como cf. M. (P.) gregaloides (HINTON, 1923). La nueva especie, denominada Iberomys huescarensis por Cuenca-Bescós \& Laplana (1995), se identificó en los niveles inferiores TD-3 a TD-6 de Gran Dolina de Atapuerca y en la Sima del Elefante (CuencaBescós et al., 2001; Made et al., 2003), y fue considerada como antecesora de Iberomys brecciensis (Cuenca-Bescós et al., 2014). Sin embargo, en un estudio realizado con anterioridad a estos trabajos por Gil (1986 y 1997) en los niveles inferiores mencionados de Gran Dolina, se documenta el registro M. (I.) brecciensis, muy característico, aunque primitivo, junto con Terricola huescarensis, denominado y caracterizado como dicho taxón por Gil (1997).

En su reciente revisión del material de Huéscar 1 sobre el que se definió la especie $M$. huescarensis, Martin (2015) señala, no obstante, varios problemas derivados de la propia determinación como especie realizada por Ruiz Bustos (1988), ya que uno de los dos paratipos es dudoso y descartable porque la sigla utilizada por este último autor (HU-195) se repite por error en 
Tabla 8.-Morfotipos del Complejo Anterocónido (ACC) del $\mathbf{M}_{1}$ de Microtus (I.) brecciensis de los yacimientos de Cuesta de la Bajada (CDLB) y Áridos (según López Martínez, 1980: Fig. 10: A; p. 171); distribución del número de ejemplares (N) y porcentaje de los mismos

\begin{tabular}{|c|c|c|c|c|c|c|c|c|c|c|c|}
\hline Morfotipo & 1 & 2 & 3 & 4 & 5 & 6 & 7 & 8 & 9 & 10 & TOTAL \\
\hline \multicolumn{12}{|l|}{ ACC - M1 } \\
\hline CDLB - N & & 3 & & & 1 & 10 & 13 & 2 & & & 29 \\
\hline$\%$ & & $10,34 \%$ & & & $3,45 \%$ & $34,49 \%$ & $44,82 \%$ & $6,90 \%$ & & & $100 \%$ \\
\hline Áridos - N & 1 & 2 & 2 & 2 & 1 & 22 & 17 & 3 & 1 & 4 & 55 \\
\hline$\%$ & $1,81 \%$ & $3,63 \%$ & $3,63 \%$ & $3,63 \%$ & $1,81 \%$ & $40 \%$ & $30,9 \%$ & $5,45 \%$ & $1,81 \%$ & $7,33 \%$ & $100 \%$ \\
\hline
\end{tabular}

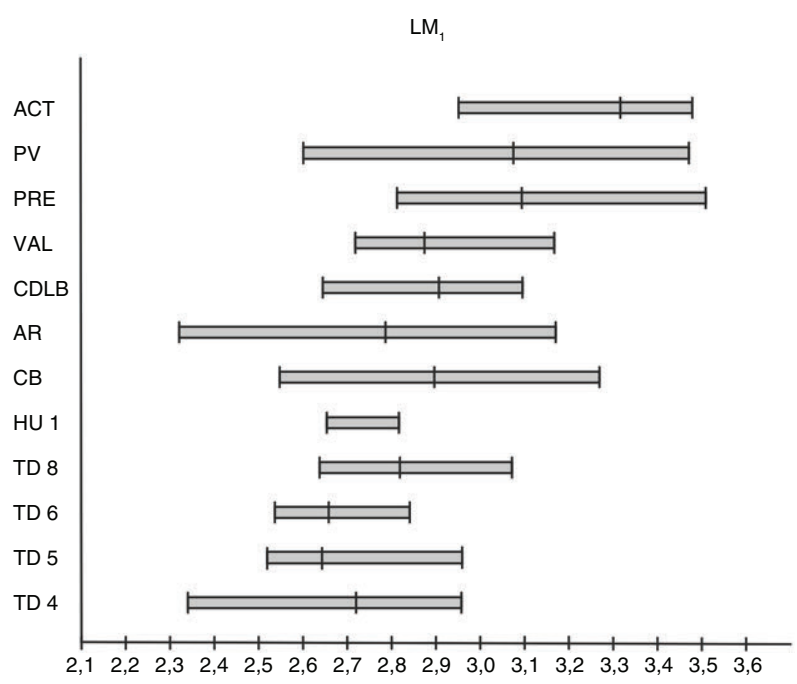

Fig. 9.-Medidas del $\mathrm{M}_{1}$ de Microtus (I.) brecciensis y Microtus (I.) cabrerae de diversos yacimientos pleistocenos y localidades actuales. Se representa en abscisas la amplitud de variación (valores mínimo y máximo) y el valor medio en milímetros de la longitud (L) de los M1 de las localidades situadas en ordenadas. Las especies, yacimientos y localidades representadas, y el número de ejemplares $(\mathrm{N})$ de cada una de ellas son: $M$. (I.) brecciensis: Atapuerca: TD 4, (N: 11); TD 5 (N: 6); TD 6 (N: 4) y TD 8, (N: 11) (Gil, 1987); Huéscar 1 (HU 1), (N: 2), (Mazo et al., 1985); Cullar de Baza (CB), (N: 22), (Ruiz Bustos \& Michaux, 1976); Áridos (AR), (N: 44), (López Martínez, 1980); Cuesta de la Bajada (CDLB), (N: 12); Valdocarros (VAL), (N: 17) (Sesé et al., 2011a); M. (I.) cabrerae: PRERESA (PRE), (N: 50), (Sesé et al., 2011b); Pinilla del Valle (PV), (N: 7), (Toni \& Molero, 1990); y Actual de Cuenca (ACT), (N: 25), (Ayarzaguena \& López Martínez, 1976).

dos $\mathrm{M}_{1}$ diferentes en la figura 3 de Mazo et al. (1985: p. 476: Fig. 3: $\mathrm{n}^{\mathrm{o}} 8 \mathrm{y} \mathrm{n}^{\mathrm{o}} 12$ ). Este error se ha puesto de manifiesto en la observación directa del material realizada por R. Martin en el MNCN cuando, junto con uno de nosotros, C.S., se cotejaron las siglas del material con las de la mencionada figura. Una vez analizada la morfología de los $\mathrm{M}_{1}$ de Huéscar 1, Martin (2015) propone tres hipótesis: 1) que la muestra sea homogénea y la variación expresada sea la de una sola especie, M. (I.) huescarensis, 2) que estén presentes ambas especies: $M$. (I.) huescarensis y $M$. (I.) brecciensis, y 3) que estén presentes estas dos especies y además una o dos adicionales de los grupos "arvaloide" y "gregaloide".
La segunda hipótesis de la coexistencia de $M$. (I.) huescarensis y $M$. (I.) brecciensis plantea, según señala Martin (2015), el problema de la presencia del antecesor y el descendiente en el mismo yacimiento, lo que supone que, o bien la descendencia de $M$. (I.) brecciensis a partir de $M$. (I.) huescarensis sería anterior a la edad de este yacimiento, o bien $M$. (I.) brecciensis sería una intrusión en Huéscar 1 de material de niveles más recientes, para lo cual se apoya en Demuro et al. (2015) que sugieren que en Huéscar 1 puede haber una mezcla de sedimentos del Pleistoceno Inferior y Medio. Demuro et al. (2015) rejuvenecen considerablemente la edad del yacimiento, asignándole por luminiscencia una cronología en torno a los 0,42-0,57 Ma, muy dispar con la propuesta anteriormente por Gibert et al. (2007) de 0,9 Ma por paleomagnetismo, que era completamente acorde con los datos biostratigráficos proporcionados por la asociación de micromamíferos y macromamíferos según Mazo et al. (1985). Sin embargo, la hipótesis de Demuro et al. (2015), no se sustenta con los datos paleontológicos del yacimiento, ya que toda la asociación faunística de macromamíferos y micromamíferos de Huéscar 1 es coherente, y la de micromamíferos, especialmente, es similar a la de los niveles inferiores de Gran Dolina de Atapuerca asignados al final del Pleistoceno Inferior, donde se han reconocido prácticamente los mismos taxones (Sesé \& Sevilla, 1996). Abundando en los argumentos sobre la edad del final del Pleistoceno Inferior de Huéscar 1, hay entre los roedores un elemento arcaico como Castillomys, un género que en Atapuerca solo se registra en los niveles más antiguos del Pleistoceno Inferior correspondientes a la Sima del Elefante (Made et al., 2003) y que desaparece en el tránsito del Pleistoceno Inferior al Pleistoceno Medio (Sesé \& Sevilla, 1996). Además, durante la realización del presente trabajo, gracias a la observación que $\mathrm{M}^{\mathrm{a}}$ Teresa Alberdi (com. pers.) hizo a uno de nosotros, C.S., sobre si se registra o no Paraethomys meini en Huéscar 1, ya que dicha cita está presente en algunas publicaciones como la mencionada de Demuro et al. (2015: Tabla 1, p. 194), que se apoya a su vez en la cita de dicho taxón en la publicación de Alberdi et al. (2001), hemos comprobado que este error podría tener su origen en la publicación de Sesé (1989: p. 191), en dónde en el apartado de los múridos la autora menciona por equivocación dicho taxón en la localidad de Huéscar 1, cuando tendría que haber puesto Huéscar 3, que es la localidad correcta según el estudio paleontológico de dichos yacimientos realizado por Mazo et al. (1985), lo que pretendemos esclarecer aquí. Paraethomys meini es una especie del Mioceno Superior y Plioceno Inferior que ya no se registra en el Villafranquiense según Sesé (2006), especie que está presente en 
el yacimiento de Huéscar 3, asignado al Rusciniense, zona MN 15, y no en el cercano yacimiento de Huéscar 1, según Mazo et al. (1985). Por todo ello, a nuestro juicio, la edad numérica propuesta por Demuro et al. (2015) no es acorde con la asociación faunística del yacimiento de Huéscar 1 y está en contradicción con los datos de los yacimientos correlacionables biostratigráficamente con el mismo y que disponen de numerosas dataciones numéricas, como son los niveles inferiores de Gran Dolina y algunos de la Sima del Elefante de Atapuerca (Berger et al., 2008; Carbonell et al., 2008; Rodríguez et al., 2011; Ollé et al., 2013), en los que tanto la biostratigrafía como la cronología son coherentes y corroboran su atribución al final del Pleistoceno Inferior.

La problemática de la especie $M$. huescarensis definida en Huéscar 1, a nuestro juicio, es la siguiente: Con respecto a los ejemplares de $\mathrm{M}_{1}$ del género Microtus, sensu lato, de Huéscar 1 figurados por Mazo et al. (1985: p. 467: Figura 3), el no 8 (HU195) fue determinado como $M$. brecciensis, identificación que siempre hemos considerado y seguimos considerando correcta en este trabajo y en trabajos anteriores (Sesé, 1994; Sesé \& Sevilla, 1996), y que mantiene Martin (2015) en algunas de sus hipótesis. Los $\mathrm{M}_{1}$ figurados por Mazo et al. (1985: p. 476: Figura 3) no 9 (HU-192), 10 (HU-193), 11 (HU-194) y 12 (HU195) fueron determinados por dichos autores como cf. Microtus (Pitymys) gregaloides, actualmente denominado Microtus (Stenocranius) gregaloides. En la descripción de este material Mazo et al. (1985) señalan que en el $\mathrm{M}_{1}$ los tres primeros triángulos están cerrados, y T4 y T5 son ampliamente confluyentes, tal como se observa en la figura, es decir, que forman lo que se suele denominar "rombo pitimiano", aunque algo imperfecto, y dicho conjunto de triángulos está a su vez prácticamente cerrado con respecto a la cúspide anterior (AC), lo que es característico según Rekovets \& Nadachowski (1995), de los géneros/ subgéneros Terricola, Stenocranius en sus primeros estadios de desarrollo y Pitymys, este último un taxón exclusivamente norteamericano (Chaline et al., 1988). Martin (2015) al revisar el material de Huéscar 1 corrobora dichos caracteres, y encuentra muchas similitudes de este material con M. gregaloides, tal como fue determinado inicialmente por Mazo et al. (1985). Ruiz Bustos (1988), sobre la figura de Mazo et al. (1985: p. 476: Fig. 3) determina la nueva especie $M$. huescarensis basándose en las siglas, sin citar el número de la figura correspondiente dentro de la Figura 3 de estos últimos autores (o.c.); así, el holotipo es el ejemplar HU-193, es decir, el $n^{\circ} 10$ de la Figura 3, y los paratipos son HU-194, es decir, el no 11, y el ejemplar HU-195. El problema reside en esta última sigla que, por equivocación de los autores de la publicación (Mazo et al., 1985), se repite en dos ejemplares de la Figura 3: en el n 8 y el n ${ }^{\circ} 12$ (la $n^{\circ} 8$ corresponde realmente a dicha sigla, mientras que la $n^{\circ} 12$ corresponde a la sigla HU-257, según nuestras propias observaciones, tal como se puede observar en la Figura 4 de Martin, 2015); razón por la que este último autor invalida las piezas que tienen la misma sigla al no saberse a ciencia cierta a cuál se refería Ruiz Bustos (1988). Ruiz Bustos (1988) no da ninguna diagnosis de la nueva especie, por lo que lo único con lo que han contado autores posteriores para reconocerla en otros yacimientos son las figuras a través de sus siglas, y han podido interpretar que es el $\mathrm{M}_{1}$ de la figura $\mathrm{n}^{\mathrm{o}} 8$ (correspondiente en realidad de Microtus (I.) brecciensis, tal como fue determinado por Mazo et al., 1985), en lugar del $\mathrm{M}_{1}$ de la figura $\mathrm{n}^{\circ} 12$ (correspondiente a Stenocranius), la que está incluida entre los paratipos de la nueva especie, mezclando de esta forma en la nueva especie ejemplares que en realidad corresponden a dos taxones distintos: Stenocranius e Iberomys. Aunque solo se puedan tener en cuenta, por lo tanto, las dos piezas $n^{\circ} 10$ y n ${ }^{\circ} 11$ de la Figura 3 de Mazo et al. (1985: Figura 3 , p. 476), como válidas para la identificación de la nueva especie $M$. huescarensis, a nuestro juicio está claro que Ruiz Bustos (1988) se refirió al material clasificado por Mazo et al. (1985) como cf. M. (P.) gregaloides, ya que, además, su denominación como Pitymys (taxón en el que también fue incluido por Mazo et al., 1985), implica unas ciertas características del $\mathrm{M}_{1}$ como la de tener los triángulos T4 y T5 ampliamente confluyentes que se observa en las figuras de dichos ejemplares y que son señaladas también en la descripción del material por estos últimos autores (o.c.).

En Huéscar 1, a nuestro juicio, la nueva especie $M$. huescarensis, tal como está definida por Ruiz Bustos (1988) sobre el material inicialmente descrito por Mazo et al. (1985) como $M$. gregaloides, es completamente similar a M. hintoni (KRETZOI, 1941) (denominación que tendría prioridad), especie en la que en todos los $\mathrm{M}_{1}$ los triángulos T4 y T5 son confluyentes, según el estudio realizado por Rekovets \& Nadachowski (1995) en la línea de especies $M$. (S.) hintoni - M. (S.) gregaloides, en la señalan que dicho carácter se va perdiendo gradualmente en poblaciones derivadas de esta última; por lo que debería incluirse en el subgénero Stenocranius y no en Iberomys, taxón al que sin embargo pertenece la especie M. (I.) brecciensis (con los cinco primeros triángulos cerrados en el $\mathrm{M}_{1}$ ), identificada correctamente en el yacimiento (Mazo et al., 1985: p. 476: Figura 3: $\mathrm{n}^{\circ} 8$ ). En Huéscar 1, por lo tanto, hay al menos dos especies del género Microtus, sensu lato, que no tienen ninguna relación filogenética entre sí. Avala esta hipótesis otro carácter importante del $\mathrm{M}_{1}$ señalado en la descripción que hacen Mazo et al. (1985: p. 478) del material de M. brecciensis: “...el complejo anterocónido asimétrico, con los ángulos LRA 4 y BRA 3 alternos y $L R A 5$ notable", lo que es muy característico de esta especie; una morfología por otra parte muy distinta del material atribuido a la nueva especie $M$. huescarensis (en nuestro opinión $M$. $(S$.) hintoni) en la que el complejo anterocónido de los distintos $\mathrm{M}_{1}$ es de tipo "arvaloide" y "gregaloide" respectivamente, tal como indica Martin (2015: p. 204).

En algunos yacimientos de finales del Pleistoceno Inferior y comienzos del Pleistoceno Medio coexisten al menos una especie perteneciente a Stenocranius y/o Terricola, con una especie de Iberomys. En los niveles inferiores de Gran Dolina TD-3 a TD-6 se encuentran M. brecciensis, con los cinco primeros triángulos cerrados en el $\mathrm{M}_{1}$ (Gil, 1986) y por otro lado, $M$. huescarensis (Gil, 1997), M. gregaloides, (Gil, 1986; Cuenca-Bescós et al., 1995) у M. arvalidens (Cuenca-Bescós et al., 1999; Made et al., 2003) en los que en el $\mathrm{M}_{1}$ los tres primeros triángulos están cerrados y los triángulos T4 y T5 son confluyentes. Con respecto a otras poblaciones determinadas como $M$. (I.) huescarensis, es decir, incluidas en Iberomys, como las de la Unidad Inferior Roja de la Sima del Elefante de Atapuerca (Cuenca et al., 2001), 
los $\mathrm{M}_{1}$ muestran los triángulos T4 y T5 confluyentes típicos de Stenocranius. En el yacimiento de Torrent de Vallparadis, con niveles del Pleistoceno Inferior, se puede observar también la distinción de $M$. gregaloides, con T4 y T5 confluyentes y $M$. huescarensis que en nuestra opinión, se trata de $M$. brecciensis ya que en el $\mathrm{M}_{1}$ los triángulos T4 y T5 están cerrados tal como se aprecia en los ejemplares A y B de la figura 6 según MinwerBarakat et al. (2011: p. 856; Fig. 6). En el yacimiento del final Pleistoceno Inferior del El Chaparral, en las fotografías de los $\mathrm{M}_{1}$ : I y J atribuidos por López-García et al. (2012: Pág. 1152: Figura 3) a $M$. (I.) huescarensis, ambos presentan los triángulos T4 y T5 confluyentes, es decir, que en nuestra opinión serían atribuibles a Stenocranius, no a Iberomys.

Por tanto, en nuestra opinión, en el género/subgénero Iberomys se incluyen solo dos especies de la línea evolutiva: $M$. (I.) brecciensis - M. (I.) cabrerae, la primera con registro desde el final del Pleistoceno Inferior y durante el Pleistoceno Medio, y la segunda desde el Pleistoceno Superior hasta la actualidad. Garrido-García y Soriguer-Escofet (2012) señalan que el registro paleontológico de Iberomys confirma su evolución dentro de la línea anagenética: $M$. (I.) brecciensis - M. (I.) cabrerae propuesta por Ayarzaguena y López Martínez (1976), Cabrera Millet et al. (1982) y López Martínez (2003), y considerada desde entonces una línea endémica de la región Ibero Occitana por su evolución principalmente en la Península Ibérica y sureste de Francia, que alcanzó también Italia.

M. (I.) brecciensis es originario de la Península Ibérica donde se registra desde el final del Pleistoceno Inferior en los yacimientos mencionados más arriba, y durante todo el Pleistoceno Medio en numerosos yacimientos (Sesé, 1994; Sesé \& Sevilla, 1996; Garrido-García y Soriguer-Escofet, 2012; Laplana \& Sevilla, 2013), dando lugar en el Pleistoceno Superior a la especie actual M. (I.) cabrerae (Ayarzaguena \& López Martínez, 1976; Cabrera-Millet et al., 1982). M. (I.) brecciensis se extendió por la mitad sureste de Francia e Italia posiblemente desde el comienzo del Pleistoceno Medio, periodo en el que Iberomys alcanzó su mayor distribución geográfica, mientras que $M$. (I.) cabrerae en el Pleistoceno Superior nunca ocupó Italia, estando restringida a la región mediterránea de Francia, de dónde desapareció en tiempos históricos recientes, y a la Península Ibérica, donde sigue habitando actualmente (aunque en áreas fragmentadas e inconexas que según Garrido-García et al., 2013 son, a grandes rasgos, la Luso-Carpetana, Montibérica, Bética y Prepirenaica), habiendo desaparecido actualmente de algunas regiones en las que, sin embargo, hay registro fósil de Iberomys hasta avanzado el Holoceno, como Cataluña (Ayarzaguena \& López Martínez, 1976; Garrido-García \& Soriguer-Escofet, 2012; Laplana \& Sevilla, 2013). López-García et al. (2015), en su estudio sobre la distribución de Iberomys en Italia durante el Pleistoceno, refieren su hallazgo en Spessa, aunque con escaso material, y en Rifreddo, yacimientos que atribuyen biostratigráficamente al Pleistoceno Inferior (aunque la asociación faunística de este último yacimiento Masini et al., 2005 lo sitúan al comienzo del Pleistoceno Medio), y señalan que, en todo caso, sería de una edad más reciente que los hallazgos de Iberomys de los niveles del Pleistoceno Inferior de Atapuerca, por lo que la expansión de Iberomys fuera de la Península Ibérica podría haber tenido lugar al final del Pleistoceno Inferior o bien en el tránsito del Pleistoceno Inferior al comienzo del Pleistoceno Medio. No obstante, un dato tan importante como es el primer registro hasta ahora de lo que podría ser $M$. (I.) brecciensis en el Pleistoceno Inferior en Italia se apoya únicamente en un material escaso y en datos biostratigráficos para situarlo en dicha edad, por lo que en nuestra opinión hay que tener cautela en las interpretaciones paleogeográficas que conlleva y esperar que nuevos hallazgos más consistentes y con dataciones numéricas en Italia y Francia confirmen o no este supuesto.

La reducción de Iberomys algunos autores la atribuyen a causas climáticas, como la aridificación del clima que sufre la región mediterránea desde el final de Pleistoceno Superior, con la consiguiente reducción de los hábitats húmedos con hierba de forma permanente que requiere (Cabrera Millet et al., 1982; Sesé, 1994; López Martínez, 2003; Laplana \& Sevilla, 2013). Garrido-García \& Soriguer-Escofet (2012) apuntan a que su reducción en épocas recientes fue debida a otras causas como la influencia humana, al destruir los hábitats húmedos en los que vive por la expansión de la agricultura desde el periodo Subboreal. Ambas hipótesis, climática y antrópica, tal como señalan Laplana \& Sevilla (2013), y en nuestra opinión, no son excluyentes, ya que la retracción del área de distribución de Iberomys podría deberse, como se ha dicho, a causas climáticas, con la consecuente reducción de sus hábitats húmedos preferenciales, acelerada en tiempos recientes por la destrucción intensiva de los mismos por la acción humana que hacen necesaria la búsqueda de medidas para prevenir su extinción (GarridoGarcía \& Soriguer-Escofet, 2012; Laplana \& Sevilla, 2013; Garrido-García et al., 2013; Fuentes et al., 2013; Pita et al., 2014; Cuenca-Bescós et al., 2014).

M. (I.) cabrerae actual es en cierto modo un roedor termófilo que vive exclusivamente en zonas climáticas mediterráneas. Por una parte es una especie típicamente mediterránea capaz de soportar las altas temperaturas veraniegas, aunque no puede vivir en áreas de clima árido con escasez de agua (Laplana \& Sevilla, 2013), y por otra, porque por el tipo de medio en el que habita de praderas y juncales, esta vegetación no puede sobrevivir si la temperatura media anual desciende por debajo de los $8^{\circ} \mathrm{C}$ (Garrido-García \& Soriguer-Escofet, 2012). Vive generalmente cerca del agua en zonas con abundante vegetación ribereña de arbustos, herbáceas y juncales, de los que se alimenta y le sirven de refugio, junto a charcas estacionales y en praderas herbáceas húmedas donde el nivel freático aflora o es muy superficial. Suele vivir en altitudes medias, entre los 500 y 1000 metros de altitud, aunque también se encuentra en altitudes más altas y más bajas, y al pie de sistemas montañosos, muy posiblemente porque estas zonas propician la existencia del tipo de hábitat y clima que requieren, ya que necesitan vegetación herbácea densa que se mantenga verde durante todo el año y por tanto tienen que ser zonas en las que la humedad del suelo sea superior a la climática (Ayarzaguena \& López Martínez, 1976; López Martínez, 1980; Blanco, 1998; Mitchell-Jones et al., 1999; Palomo y Gisbert, 2002; Laplana \& Sevilla, 1913; Pita et al., 2014).

\section{Microtus (Terricola) duodecimcostatus (SÉLYS- LONGCHAMPS, 1839)}


Topillo mediterráneo

(Fig. 7: 9 y 10)

\section{Material por niveles y medidas:}

Hay 6 fr. de mand. con el $\mathrm{M}_{1}$ (una de ellas con la serie dentaria $\mathrm{M}_{1}-\mathrm{M}_{2}-\mathrm{M}_{3}$ y cinco con el $\mathrm{M}_{2}$ ); el resto son dientes aislados.

-16: $1 \mathrm{M}_{1}$ der.; $3 \mathrm{M}_{1}$ izq.; NMI: 3.

-CB3: $21 \mathrm{M}_{1}$ der.; $12 \mathrm{M}_{1}$ izq.; NMI: 21.

-CB3+CB2: $1 \mathrm{M}_{1}$ der.; $3 \mathrm{M}_{1}$ izq.; NMI: 3.

-CB2: $7 \mathrm{M}_{1}$ der.; $6 \mathrm{M}_{1}$ izq.; NMI: 7.

-CB2+CB1+P: $1 \mathrm{M}_{1}$ der.; $1 \mathrm{M}_{1}$ izq.; NMI: 1 .

-CB1: $3 \mathrm{M}_{1}$ der.; $3 \mathrm{M}_{1}$ izq.; NMI: 3 .

Las medidas de los $\mathrm{M}_{1}$ se dan en la Tabla 9.

\section{Descripción y discusión:}

La morfología del $\mathrm{M}_{1}$ es la característica de Microtus (T.) duodecimcostatus; en vista oclusal consta de: un lóbulo posterior; los tres primeros triángulos (T1, T2 y T3) cerrados; dos triángulos confluyentes (T4 y T5) constituyendo el rombo pitimiano más o menos abierto al complejo anterior; complejo anterior formado por dos triángulos opuestos y confluyentes (T6 y T7) que forman un segundo rombo pitimiano que se abre por un amplio cuello al anterocónido (es decir, que los ángulos entrantes BRA 4 y LRA 5 según la nomenclatura de López Martínez, 1980, o ángulos entrantes 8 y 9 según la de Brunet-Lecomte et al., 1987, son poco profundos); y anterocónido de contorno redondeado u ovalado. Aunque Brunet-Lecomte et al. (1987) en su estudio sobre la morfología dentaria de $M$. (T.) duodecimcostatus y $M$. (T.) lusitanicus (GERBE, 18979) actuales señalan la dificultad de diferenciar los dientes de una y otra especie, hay algunos caracteres del $\mathrm{M}_{1}$ que permiten distinguirlas: en la primera especie el segundo rombo pitimiano formado por T7 y T8 está menos desarrollado; la abertura o confluencia de este segundo rombo pitimiano con el anterocónido es mayor (es decir que los ángulos entrantes 8 y 9 son menos profundos); el anterocónido es más redondeado; y la inclinación del complejo anterior con respecto al eje de simetría es más débil que en la segunda especie (BrunetLecomte et al., 1987; Rodríguez Prieto, 2013), caracteres que se encuentran en la población de Cuesta de la Bajada. Asimismo, la longitud del $\mathrm{M}_{1}$, aunque no parece ser un valor discriminante, porque hay un amplio solapamiento de la amplitud de variación de ambas, es mayor en $M$. (T.) duodecimcostatus que en $M$. (T.) lusitanicus (Chaline, 1972; Brunet-Lecomte et al., 1987).

La talla $\left(\mathrm{L} \mathrm{M}_{1}\right)$ de la población de Cuesta de la Bajada entra dentro de la variabilidad de la de $M$. (T.) grupo duodecimcostatus de Cueva del Agua (López Martínez \& Ruiz Bustos, 1977). La población de Pinilla del Valle identificada como M. (T.) grupo duodecimcostatus por Toni \& Molero (1990) presenta

Tabla 9.- Medidas de los $\mathbf{M}_{1}$ de Microtus (T.) duodecimcostatus de Cuesta de la Bajada.

\begin{tabular}{|c|c|c|c|c|c|c|c|c|}
\hline \multirow[b]{2}{*}{ DIENTE } & \multirow[b]{2}{*}{$\mathrm{N}$} & \multicolumn{3}{|c|}{ LONGITUD } & \multirow[b]{2}{*}{$\mathrm{N}$} & \multicolumn{3}{|c|}{ ANCHURA } \\
\hline & & MíN. & MED. & MÁX. & & MíN. & MED. & MÁX. \\
\hline$M_{1}$ & 23 & 2,54 & 2,68 & 2,85 & 29 & 0,91 & 0,99 & 1,05 \\
\hline
\end{tabular}

una variabilidad extraordinaria, con unos valores mínimos muy por debajo de los de las poblaciones de Cueva del Agua y Cuesta de la Bajada, y unos valores máximos mucho mayores. Posteriormente Laplana et al. (2013) clasifican el topillo del final del Pleistoceno Medio del Sondeo Galería (Pinilla del Valle) como M. (T.) gr. lusitanicus-duodecimcostatus, mientras que el topillo del yacimiento del Pleistoceno Superior de Camino (denominado anteriormente Pinilla del Valle por Toni \& Molero, 1990) Laplana \& Sevilla (2006) lo clasifican como M. (T.) lusitanicus y posteriormente Laplana et al. (2013) vuelven a determinarlo como M. (T.) gr. duodecimcostatus. La zona centro peninsular donde se ubican dichos yacimientos es actualmente una zona de amplio solapamiento de ambas especies y puede que lo fuera también durante el Pleistoceno Medio final y Pleistoceno Superior, lo que puede hacer difícil su clasificación en una u otra especie y explicaría la gran amplitud de talla que se observa en las medidas de Toni \& Molero (1990), que podría ser en realidad la mezcla de ambas especies ya que, aunque la de $M$. (T.) lusitanicus es más pequeña que M.(T.) duodecimcostatus, sus tallas se solapan. La talla de la población de $M$. (T.) duodecimcostatus del yacimiento del Pleistoceno Superior de La Carigüela (Ruiz Bustos \& García Sánchez, 1977; Ruiz Bustos et al., 1982) es mayor que la de la población de Cuesta de la Bajada. Algunas poblaciones actuales de M. (T.) duodecimcostatus alcanzan unos valores máximos más altos que los de Cuesta de la Bajada, y las de $M$. (T.) lusitanicus tienen unos valores mínimos más pequeños, estando la población de Cuesta de la Bajada en la zona intermedia de solapamiento de ambas.

Brunet-Lecomte et al. (1987) sugieren que M. (T.) lusitanicus es una forma derivada de $M$. (T.) duodecimcostatus por cladogénsis en el Pleistoceno. Según el estudio realizado por Rodríguez Prieto (2013) en poblaciones actuales mediante el uso de secuencias mitocondriales y la reconstrucción del árbol de especies con diversas poblaciones de la Península Ibérica, considera que $M$. (T.) duodecimcostatus y $M$. (T.) lusitanicus son especies hermanas que se estima que divergieron hace unos 0,65 millones de años, es decir, durante el Pleistoceno Medio. En el sureste de Francia el registro de $M$. (T.) duodecimcostatus comienza en la segunda mitad del Pleistoceno Medio, mientras que en la España peninsular, hasta ahora el registro fósil conocido comenzaba en yacimientos situados biostratigráficamente al final del Pleistoceno Medio (Sesé, 1994; Sesé \& Sevilla, 1996; Arribas, 2004), aunque su hallazgo en el yacimiento de Cuesta de la Bajada supone su registro en el Pleistoceno Medio avanzado por no final. Por otra parte, $M$. (T.) lusitanicus tanto en el suroeste de Francia como en la España peninsular se registra a partir del Pleistoceno Superior (Arribas, 2004). Los datos del registro fósil parecen sugerir, por tanto, que la aparición de $M$. (T.) lusitanicus es más reciente que los datos indicados por Rodríguez Prieto (2013), y que tuvo lugar en el Pleistoceno Superior, como han señalado diversos autores (Brunet-Lecomte \& Chaline, 1990; Chaline et al., 1999).

El yacimiento de Cuesta de la Bajada es hasta ahora, por su datación absoluta, el yacimiento más antiguo en el que se registra $M$. (T.) duodecimcostatus en la Península Ibérica, especie cuya aparición sería por tanto en el último tercio del Pleistoceno Medio y no al final del Pleistoceno Medio como 
estaba documentado hasta ahora (Sesé, 1994; Sesé \& Sevilla, 1996; Arribas, 2004). En Madrid su registro conocido es más tardío ya que no aparece en los yacimientos del Pleistoceno Medio de Áridos (López Martínez, 1980) y Valdocarros (Sesé et al., 2011a) sino en el del final del Pleistoceno Medio de Arriaga (Sesé \& López Martínez, 2013) y en los yacimientos ya del Pleistoceno superior de PRERESA (Sesé et al., 2011 a) y Pinilla del Valle (Toni \& Molero, 1990; Laplana \& Sevilla, 2006; Laplana et al., 2013), así como en numerosos yacimientos del resto de la Península Ibérica del Pleistoceno Superior y Holoceno, excepto en la región Cantábrica (Sesé, 2005), en la que actualmente sigue ausente en su mayor parte, sobre todo en la zona occidental.

M. (T.) duodecimcostatus es una especie endémica de la región sudoccidental europea que actualmente se distribuye en el sudeste de Francia y en la Península Ibérica excepto en el noroeste; mientras que $M$. (T.) lusitanicus es otra especie endémica que solo se encuentra en el triángulo noroeste de la Península Ibérica y marginalmente en el sudoeste de Francia, aunque ambas tienen una gran zona de solapamiento especialmente en la mayor parte de Castilla- León, norte de Navarra, sur del País Vasco y oeste de La Rioja (Mitchell-Jones et al., 1999; Palomo \& Gisbert, 2002; Rodríguez Prieto, 2013). En España $M$. (T.) duodecimcostatus se registra desde el Pleistoceno Medio en yacimientos de prácticamente las mismas áreas en las que habita actualmente, y $M$. (T.) lusitanicus en numerosos yacimientos del Pleistoceno Superior de los Altos Pirineos, Región Cantábrica, y centro peninsular (Sesé \& Sevilla, 1996; Arribas, 2004; Sesé, 2005; López García, 2008).

Es una especie propia de espacios abiertos, en áreas climáticas con influencia mediterránea, que requiere suelos que sean blandos, estables y húmedos fácilmente excavables y con abundante vegetación herbácea, y se encuentra en zonas desde el nivel del mar hasta los $3.000 \mathrm{~m}$ de altura en Sierra Nevada (Blanco, 1998; Palomo \& Gisbert, 2002; Mitchell-Jones et al., 1999). En el estudio realizado por Brunet-Lecomte (1991) sobre poblaciones actuales de $M$. (T.) duodecimcostatus en el noroeste de la Península Ibérica concluye que los factores limitantes de su área de distribución confirman que es una especie propia del clima mediterráneo que no puede subsistir en zonas de clima húmedo y de veranos poco cálidos como el clima atlántico. Mitchell-Jones et al. (1999) señala que en amplias zonas de la Península Ibérica es el único representante del género Microtus y también que es la especie de este género que mejor tolera la sequía y las temperaturas adversas.

\section{Consideraciones finales sobre la fauna: conclusiones}

El conocimiento del yacimiento de Cuesta de la Bajada, que reúne una industria del Paleolítico Medio antiguo junto con una variada asociación de macromamíferos y micromamíferos, se completa con el presente estudio de estos últimos, cuyos resultados permiten realizar algunas consideraciones de orden sistemático, evolutivo, biostratigráfico y paleoambiental.
La asociación de micromamíferos determinada en este trabajo es la siguiente: Lagomorpha: Oryctolagus cuniculus; Eulipotyphla: Crocidura cf. russula, cf. Sorex sp., Neomys sp., Soricidae indet. y Talpa sp.; y Rodentia: Eliomys quercinus, Apodemus cf. sylvaticus, Cricetulus (Allocricetus) bursae, Arvicola aff. sapidus, Microtus (Iberomys) brecciensis y Microtus (Terricola) duodecimcostatus. Es una asociación característica del Pleistoceno Medio, lo que es acorde con lo que indica biostratigráficamente la asociación de macromamíferos registrada en el yacimiento: Carnivora: Canis lupus; Proboscidea: Elephas (Palaeoloxodon) antiquus; Perissodactyla: Stephanorhinus cf. hemitoechus y Equus chosaricus; Artiodactyla: Cervus elaphus, Bos primigenius, Rupicapra rupicapra y Capra sp. (Santonja et al., 2014). El estadio evolutivo de Cricetulus (A.) bursae, Arvicola aff. sapidus y Microtus (I.) brecciensis le aproximan biostratigráficamente a las poblaciones de dichas especies de algunos yacimientos del Pleistoceno Medio avanzado, pero no final, de la Península Ibérica, como se ha dicho en los apartados correspondientes, lo que es acorde con las dataciones numéricas obtenidas en el yacimiento (243-337 ka) que le sitúan en el MIS 8 o 9 según Santonja et al. (2014).

De los taxones de micromamíferos mencionados, Cricetulus (A.) bursae se extinguió al final del Pleistoceno Superior (Sesé, 1994; Sesé \& Sevilla, 1996) y Microtus (I.) brecciensis dio lugar por evolución en el Pleistoceno Superior a la especie actual Microtus (I.) cabrerae (Ayarzaguena \& López Martínez, 1976; Cabrera-Millet et al., 1982); los demás viven hoy día en la Península Ibérica, incluida esta última especie. La mayoría de ellos se distribuye también ampliamente en el resto de Europa excepto tres especies que son endémicas de Europa sudoccidental: Microtus (I.) cabrerae que está restringido a la Península Ibérica, excepto en el tercio norte; Microtus (T.) duodecimcostatus que solo se encuentra en la Península Ibérica, excepto en el noroeste, y en el sudeste de Francia; y Arvicola sapidus que solo se distribuye en la Península Ibérica y Francia. En cuanto a Cricetulus (A.) bursae su probable representante actual más próximo, Cricetulus migratorius, está ausente de la mayor parte de Europa excepto de la parte este más próxima a Asia que es en donde tiene una amplia distribución.

Son comunes actualmente en la zona sur de la provincia de Teruel donde se ubica el yacimiento: Oryctolagus cuniculus, Crocidura russula, Eliomys quercinus, Apodemus sylvaticus y Microtus (T.) duodecimcostatus. Arvicola sapidus tiene poca distribución en la provincia de Teruel excepto algunos hallazgos en la parte sudeste y este. Microtus (I.) cabrerae está prácticamente ausente de la provincia de Teruel excepto en el extremo sur colindante con la comunidad valenciana (Palomo \& Gisbert, 2002, Garrido-García et al., 2013). De las dos especies del género Neomys que hay en la Península Ibérica actualmente, Neomys fodiens y Neomys anomalus, solo de esta última hay algunos registros distribuidos por la provincia de Teruel. Del género Talpa, hay registros actuales de la especie Talpa occidentalis en el sur de la provincia de Teruel, mientras que de Sorex no hay ninguno en toda la provincia, aunque en este último caso su cita en el yacimiento de Cuesta de la Bajada es con ciertas reservas (cf. Sorex sp.) como se dijo anteriormente. Erinaceus, un género que, aunque no se ha encontrado en la campañas de 
excavación de las que procede el material objeto de este estudio, se citó en el yacimiento en las publicaciones de las primeras excavaciones (Santonja et al., 1990 y 1992; Moissenet, 1993), es también muy común actualmente en la provincia de Teruel.

Con respecto a los micromamíferos obtenidos en las primeras excavaciones realizadas en el yacimiento (Santonja et al., 1990 y 1992; Moissenet, 1993), gracias a las campañas de los últimos años se ha ampliado la lista faunística en varios taxones: Neomys sp., cf. Sorex sp. Talpa sp. y Eliomys quercinus, y sin embargo, como se ha dicho, no se ha encontrado ningún resto de Erinaceus sp., mencionado por dichos autores; también se han cambiado las determinaciones taxonómicas de aquellos autores (o.c.) de Microtus brecciensis-dentatus y Pitymys cf. pyrenaicus por Microtus (I.) brecciensis y Microtus (T.) duodecimcostatus respectivamente.

En cuanto a la sistemática, al haberse encontrado una población relativamente numerosa de Microtus (I.) brecciensis, se ha podido caracterizar su estadio evolutivo. Hemos analizado muchos de los trabajos realizados sobre el género/subgénero Iberomys y las especies que en él se incluyen, y revisado el material depositado en el MNCN del género Microtus, sensu lato, de Huéscar 1 publicado por Mazo et al. (1985), yacimiento en el que tiene lugar uno de los registros más antiguos de Iberomys, lo que nos ha llevado a concluir que éste taxón sólo comprende las especies Microtus (I.) brecciensis y Microtus (I.) cabrerae. En nuestra opinión, la nueva especie $M$. huescarensis, tal como fue definida en Huéscar 1 por Ruiz Bustos (1988) sobre el material inicialmente denominado por Mazo et al. (1985) como M. gregaloides, es completamente similar a M. hintoni (denominación que tendría prioridad), y debería incluirse por tanto en el subgénero Stenocranius y no en Iberomys como se venía haciendo hasta ahora por parte de algunos autores. En el yacimiento del final del Pleistoceno Inferior de Huéscar 1 se registra por tanto la coexistencia de Stenocranius e Iberomys (M. (I.) brecciensis) (taxones que por lo tanto no están relacionados filogenéticamente), coexistencia que ocurre también en otros yacimientos como los niveles inferiores del Pleistoceno Inferior de Gran Dolina y otros de dichas edades.

El material dentario del yacimiento de Cuesta de la Bajada está, en general, en bastante buen estado de conservación. De casi todos los taxones identificados se han encontrado algunos fragmentos mandibulares (37 en total), bien con algunos dientes o sin ellos, aunque la mayoría de los dientes aparecen aislados. Aunque la mayoría de los dientes se conservan muy bien, hay algunos que presentan la corrosión característica producida por los jugos gástricos de predadores, muy posiblemente de aves rapaces (Andrews, 1990). Esta corrosión parece diferencial según el grado de la misma y el tipo de taxón. En Cricetulus (A.) bursae, 9 de 32 molares (el 28\%) presentan el esmalte en general muy corroído, sin embargo en Apodemus sylvaticus, que tiene una estructura dental bastante similar, solo uno de 10 molares $(10 \%)$ presenta algo de corrosión. En cuanto a los arvicolinos, de $33 \mathrm{M}_{1}$ de Microtus (I.) brecciensis, 14 ejemplares (42,5\%) presentan una corrosión de débil a moderada; y de $62 \mathrm{M}_{1}$ de Microtus (T.) duodecimcostatus, 27 dientes presentan corrosión $(43,5 \%)$ que en 25 es de débil a moderada y solo en 2 es fuerte. Es muy notable el fuerte grado de corrosión que presentan la

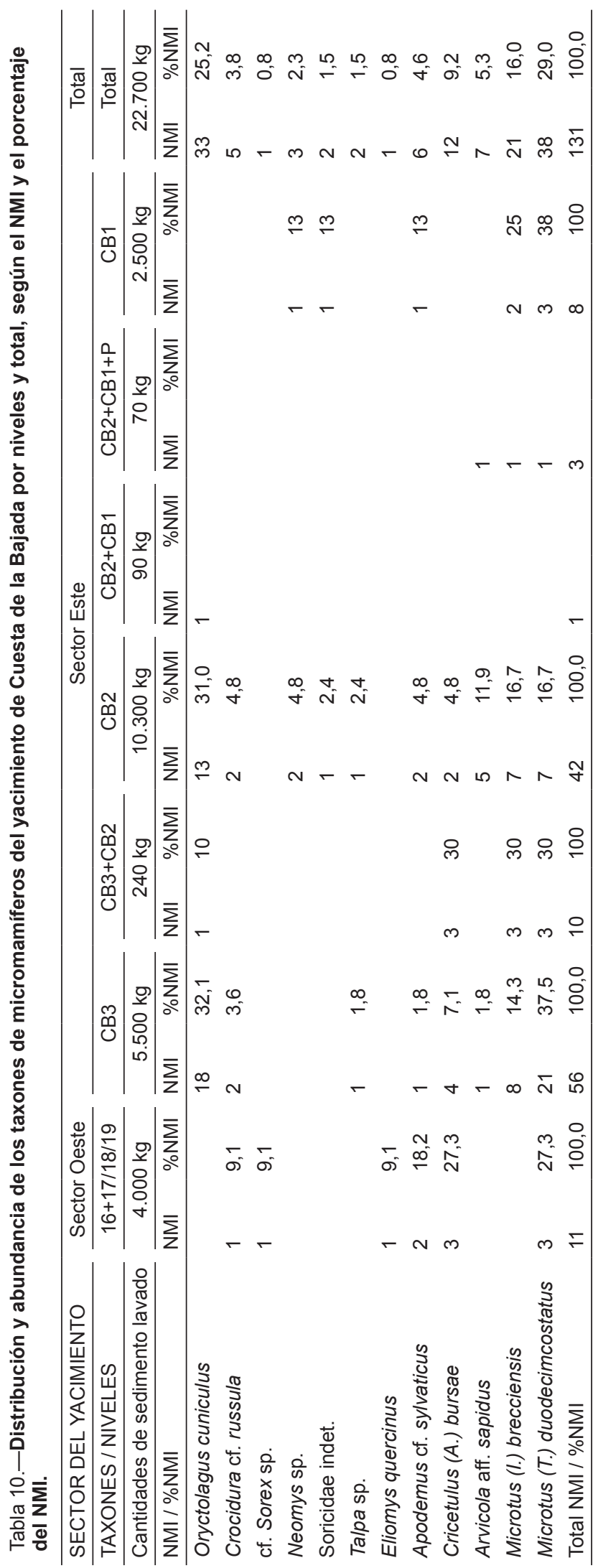




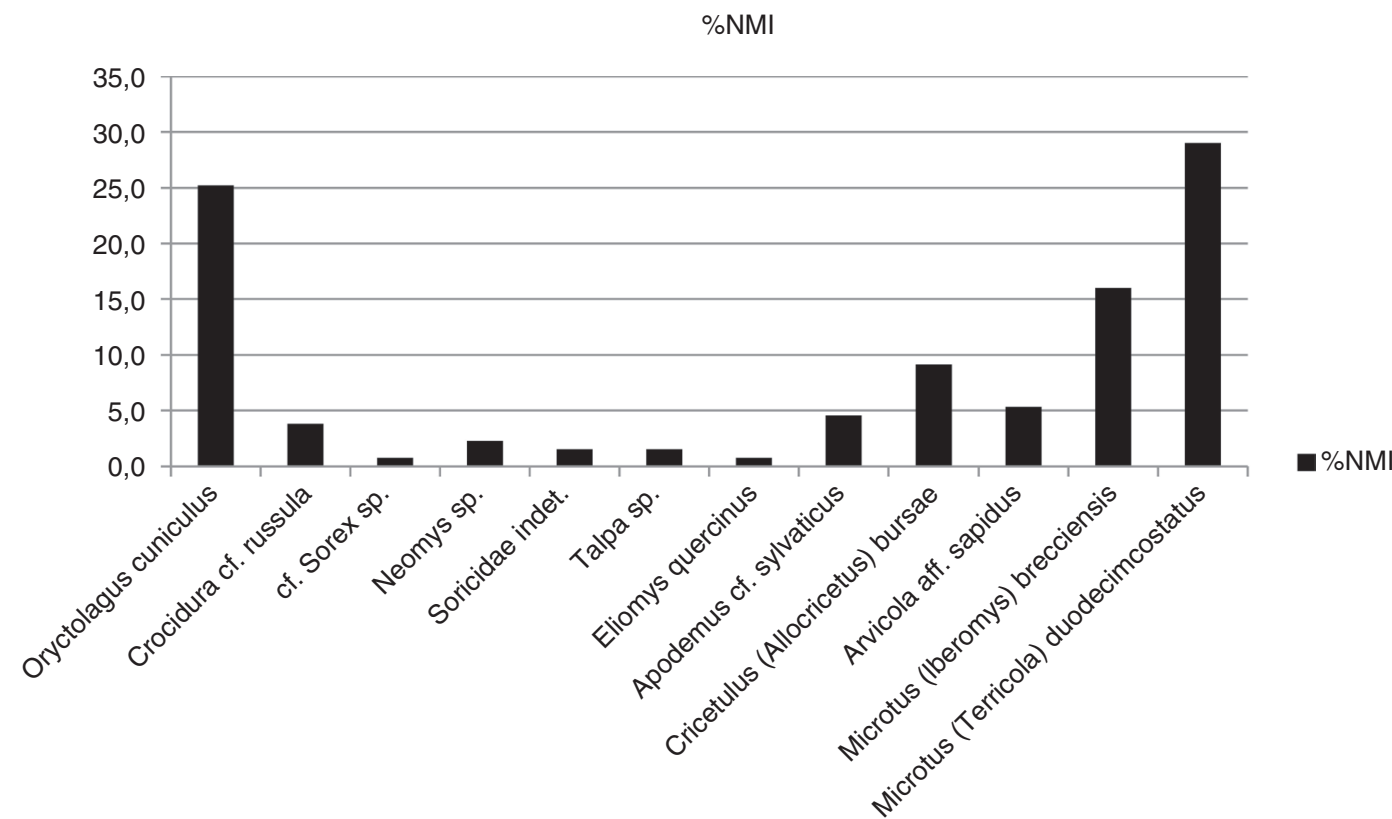

Fig. 10.-Representación porcentual (a partir de los datos de la Tabla 10) de los taxones de micromamíferos del conjunto total de niveles del yacimiento de Cuesta de la Bajada.

tercera parte de los dientes del cricétido, a diferencia de la débil corrosión de los dientes que presentan huellas de digestión en los demás grupos (múridos y arvicolinos). Otro dato que podría avalar este tipo de causa por predación en el origen de la acumulación de restos es la presencia de algunos individuos juveniles de varios grupos taxonómicos en los que es posible distinguir la edad relativa: hay 8 premolares de individuos juveniles de Oryctolagus cuniculus, 4 molares de individuos juveniles de Microtus (I.) brecciensis y 2 de Microtus (T.) duodecimcostatus.

Con respecto a la abundancia relativa de los taxones de micromamíferos en el conjunto de niveles del yacimiento (Tabla 10 y Figura 10), la especie más abundante es Microtus (T.) duodecimcostatus con un $29 \%$ del NMI, seguida por Oryctolagus cuniculus con un 25,2\%, Microtus (I.) brecciensis con el 16\% y Cricetulus (A.) bursae con el 9,2\%. Las demás especies están en general escasamente representadas, por debajo del $6 \%$, dos de ellas con solo un $0,8 \%$ cada una. Los arvicolinos en conjunto son el grupo mejor representado con el 50,3\% del NMI (66 de 131 NMI). Aunque por niveles esta representación varía, en los dos que tienen mayor valor del NMI se pueden realizar las siguientes observaciones: en el nivel CB3 se mantiene el orden relativo de los taxones más abundantes: Microtus (T.) duodecimcostatus con el 37,5\%, Oryctolagus cuniculus con el 32,1\%, Microtus (I.) brecciensis con el 14,3\% y Cricetulus (A.) bursae con el 7,1\% quedando los demás muy por debajo de estos porcentajes, mientras que en el nivel CB2 el taxón más abundante es Oryctolagus cuniculus con un $31 \%$ seguido de Microtus (T.) duodecimcostatus y Microtus (I.) brecciensis igualmente representados por un 16,7\% cada uno y el cuarto taxón más abundante es Arvicola aff. sapidus con el $11,9 \%$. Estas pequeñas diferencias no nos parecen suficientes para tenerlas en cuenta en deducciones de tipo paleoambiental teniendo en cuenta, entre otras razones de tipo tafonómico, que las cantidades de sedimento de las que proviene la fauna son dispares en ambos casos.

Todos los taxones registrados en el yacimiento tienen representantes actuales que son buenos indicadores en general del tipo de medio y clima en el que viven preferencialmente. Prácticamente todos los taxones indican en general un buen desarrollo de la cobertura vegetal, bien sea herbácea, arbustiva y en menor medida arbórea. No hay taxones estrictamente forestales aunque algunos podrían frecuentar zonas boscosas o con densa vegetación (Erinaceus, Eliomys quercinus y Apodemus), zonas más abiertas de borde de bosque con buena cobertura vegetal arbustiva o herbácea (Crocidura russula y Talpa), dehesas con abundante matorral y pastizales (Oryctolagus cunicu$l u s$ ), y hay otros propios de espacios abiertos de suelos húmedos con abundante vegetación herbácea (Microtus (T.) duodecimcostatus) o escasa vegetación y praderas secas (Cricetulus). Hay taxones ripícolas ligados por lo general a cursos de agua permanentes como el género Neomys y Arvicola sapidus, aunque también se pueden encontrar ambos en praderas húmedas; esta última especie requiere una abundante vegetación ribereña de la que se alimenta. También, aunque no tan estrictamente ripícola, Microtus (I.) cabrerae actual (descendiente de M. (I.) brecciensis) está ligado generalmente a riberas de zonas de agua que pueden ser cursos de agua o charcas estacionales y también praderas húmedas, pero con abundante vegetación herbácea de la que se alimenta.

Teniendo en cuenta que los taxones más abundantes: Microtus (T.) duodecimcostatus, Oryctolagus cuniculus, Microtus (I.) brecciensis y Cricetulus (A.) bursae suman el 79,4\% del NMI, desde un punto de vista paleoambiental se puede decir que en general parece que predominan los espacios abiertos en los que podría haber alguna zona arbolada por la presencia y abundancia 
Tabla 11.-Abundancia de los taxones de micromamíferos de los yacimientos con dataciones absolutas del Pleistoceno Superior de PRERESA (P) (Sesé et al., 2011b) y Pleistoceno Medio de Valdocarros (V) (Sesé et al., 2011a; Panera et al., 2011), Cuesta de la Bajada (CB) y Áridos (Á) (López Martínez, 1980; Panera et al., 2011). Santonja et al. (1990 y 1992) y Moissenet (1993) citan Erinaceus sp. en CB (de ahí la X en dicho taxón para indicar su presencia en dicho yacimiento), que sin embargo posteriormente en nuestras excavaciones no se ha vuelto a encontrar.

\begin{tabular}{|c|c|c|c|c|c|c|c|c|}
\hline \multirow[b]{3}{*}{ TAXONES } & \multirow{2}{*}{\multicolumn{2}{|c|}{$\begin{array}{l}\text { PRERESA } \\
\text { (Pleis. Sup.) } \\
84 \pm 5,6 \mathrm{ka}\end{array}$}} & \multirow{2}{*}{\multicolumn{2}{|c|}{$\begin{array}{c}\begin{array}{c}\text { Valdocarros } \\
\text { (Pleis. Med.) }\end{array} \\
245 \pm 47-262 \pm 6,8 \mathrm{ka}\end{array}$}} & \multirow{2}{*}{\multicolumn{2}{|c|}{$\begin{array}{c}\begin{array}{c}\text { Cuesta Bajada } \\
\text { (Pleis. Med.) }\end{array} \\
243-337 \text { ka }\end{array}$}} & \multicolumn{2}{|c|}{$\begin{array}{c}\text { Áridos } \\
\text { (Pleis. Med.) }\end{array}$} \\
\hline & & & & & & & $332 \pm 38$ & $79 \pm 45 \mathrm{ka}$ \\
\hline & NMI & $\% \mathrm{NMI}$ & NMI & $\% \mathrm{NMI}$ & NMI & $\% \mathrm{NMI}$ & $\mathrm{NMI}$ & $\% \mathrm{NMI}$ \\
\hline $\begin{array}{l}\text { Erinaceus europaeus (P)/ } \\
\text { Erinaceus sp. (CB) }\end{array}$ & 1 & $0,6 \%$ & 2 & $3 \%$ & $x$ & & & \\
\hline $\begin{array}{l}\text { Crocidura russula (P) / C. aff. } \\
\text { russula (V y Á) / C. cf. russula (CB) }\end{array}$ & 3 & $1,8 \%$ & 3 & $5 \%$ & 5 & $3,8 \%$ & 2 & $1,9 \%$ \\
\hline cf. Sorex sp. (CB) / Sorex sp. (Á) & & & & & 1 & $0,8 \%$ & 1 & $0,9 \%$ \\
\hline Neomys sp. & & & & & 3 & $2,3 \%$ & & \\
\hline Soricidae indet. & & & & & 2 & $1,5 \%$ & & \\
\hline Talpa sp. & & & & & 2 & $1,5 \%$ & & \\
\hline Rhinolophus ferrumequinum & 1 & $0,6 \%$ & & & & & & \\
\hline Pipistrellus sp. & & & & & & & 1 & $0,9 \%$ \\
\hline Vespertilionidae indet. & & & & & & & 1 & $0,9 \%$ \\
\hline Eliomys quercinus & 4 & $2,4 \%$ & 1 & $2 \%$ & 1 & $0,8 \%$ & 4 & $3,7 \%$ \\
\hline Castor fiber & & & 2 & $3 \%$ & & & 2 & $1,9 \%$ \\
\hline $\begin{array}{l}\text { Apodemus sp. (P y V) / Apodemus } \\
\text { cf. sylvaticus (Á y CB) }\end{array}$ & 10 & $5,9 \%$ & 6 & $10 \%$ & 6 & $4,6 \%$ & 15 & $13,9 \%$ \\
\hline Cricetulus (Allocricetus) bursae & 4 & $2,4 \%$ & 4 & $7 \%$ & 12 & $9,2 \%$ & 7 & $6,5 \%$ \\
\hline Arvicola aff. sapidus & 14 & $8,3 \%$ & 2 & $3 \%$ & 7 & $5,3 \%$ & 6 & $5,6 \%$ \\
\hline $\begin{array}{l}\text { Microtus (I.) cabrerae }(P) / \text { Microtus } \\
\text { (I.) brecciensis (V, Á y CB) }\end{array}$ & 82 & $48,5 \%$ & 18 & $31 \%$ & 21 & $16 \%$ & 29 & $26,9 \%$ \\
\hline Microtus (T.) duodecimcostatus & 1 & $0,6 \%$ & & & 38 & $29 \%$ & & \\
\hline $\begin{array}{l}\text { Oryctolagus cuniculus (P, V y CB) / } \\
\text { Oryctolagus cf. lacosti (Á) }\end{array}$ & 49 & $29 \%$ & 21 & $36 \%$ & 33 & 25,2 & 38 & $35,2 \%$ \\
\hline Lepus sp. & & & & & & & 2 & $1,9 \%$ \\
\hline TOTAL & 169 & $100 \%$ & 59 & $100 \%$ & 131 & $100 \%$ & 108 & $100 \%$ \\
\hline
\end{tabular}

del conejo, y en menor medida de Erinaceus, Eliomys quercinus, Apodemus, Crocidura russula y Talpa.

Es posible que el clima fuera relativamente algo más húmedo que el actual y el río cercano algo más caudaloso y con mayor vegetación en los alrededores por la presencia de taxones que parece que actualmente son raros o no se encuentran en la zona del entorno del yacimiento como Neomys, Arvicola sapidus y Microtus (I.) cabrerae.

En cuanto a la temperatura, hay algunos taxones termófilos (Apodemus y Crocidura russula), otros de clima templado (Eliomys quercinus), y en general abundan los propios de zonas de clima mediterráneo como Microtus (T.) duodecimcostatus (que por otra parte es la especie más abundante), Microtus (I.) brecciensis (también relativamente abundante), e incluso Arvicola sapidus que solo se encuentra en Europa sudoccidental, y Oryctolagus cuniculus (la segunda especie en abundancia en el yacimiento) que actualmente suele ser mucho más abundante en zonas con influencia del clima mediterráneo. El clima por tanto podría haber sido de tipo mediterráneo similar o incluso algo más benigno que el actual por la presencia de taxones que actualmente parecen estar en regresión o casi desparecidos de la región. Con respecto a esto último, hay que tener en cuenta no solo los cambios climáticos acaecidos desde el Pleistoceno Medio que han podido estar en el origen de los cambios en la distribución geográfica de algunos micromamíferos, sino también el hecho de que la reducción o desaparición actualmente de algunos taxones de muchas zonas en las que sin embargo habitaron durante el Pleistoceno Medio, Pleistoceno Superior y gran parte del Holoceno, como parece que está documentado por el registro fósil de Microtus (I.) brecciensis y su descendiente Microtus (I.) cabrerae (Garrido-García \& Soriguer-Escofet, 2012; Laplana \& Sevilla, 2013), ha podido estar influida también por la presencia humana, especialmente en tiempos recientes, al modificar el entorno haciendo desparecer sus biotopos preferenciales, en este caso los humedales.

El yacimiento de Cuesta de la Bajada es hasta ahora uno de los más antiguos en los que se registra por primera vez Microtus (T.) duodecimcostatus, es decir, en el último tercio del Pleistoceno Medio y no al final del Pleistoceno Medio como estaba documentado hasta ahora (Sesé, 1994; Sesé \& Sevilla, 1996; Arribas, 2004). En las terrazas del Jarama y Manzanares de Madrid esta especie 
está ausente en los yacimientos del Pleistoceno Medio avanzado de Áridos y Valdocarros, y su primer registro es al final del Pleistoceno Medio en el yacimiento del Arenero de Arriaga, encontrándose también en el Pleistoceno Superior en el yacimiento de PRERESA (Sesé \& López Martínez, 2013). En este último yacimiento, muy rico en restos de micromamíferos (Tabla 11), Microtus (T.) duodecimcostatus es sumamente escaso con tan sólo el 0,6\% del NMI. En Cuesta de la Bajada, sin embargo, es el taxón de micromamíferos más abundante ( $29 \%$ del NMI), lo que, junto a su temprano registro, puede ser debido a la situación geográfica del yacimiento en la región Mediterránea, que por tanto podría tener ya entonces un clima con más influencias mediterráneas que los yacimientos del centro de la Península Ibérica, y por tanto unas condiciones ambientales mucho más favorables a su expansión.

Con respecto a los mencionados yacimientos de Madrid, hay sin embargo bastantes similitudes. La mayoría de los taxones son comunes en ambas cuencas (Tabla 11). Las únicas diferencias en el registro de taxones, a parte de las ya mencionadas, son la presencia de Castor fiber en los yacimientos de Madrid de Valdocarros y Áridos, y varios quirópteros en este último, taxones que no se registran en Cuesta de la Bajada, y la ausencia en los yacimientos de Madrid de los géneros Neomys y Talpa, que sin embargo se registran en Cuesta de la Bajada. La existencia de medios fluviales o cursos de agua permanente está documentada pues en ambas zonas geográficas no solo por la presencia en los yacimientos de Madrid de Castor fiber y en Cuesta de la Bajada del género Neomys, sino también por la presencia en ambas zonas de Arvicola sapidus y Microtus (I.) brecciensis, una especie cuyo representante actual Microtus (I.) cabrerae, si no estrictamente fluvial, está ligada a riberas de masas de agua o praderas muy húmedas. Por otra parte, es notable la abundancia en ambas regiones geográficas de Oryctolagus cuniculus, la especie más abundante en los yacimientos de Áridos (35,2\% del NMI) y Valdocarros (36\% del NMI) y segunda en abundancia en PRERESA (29\% del NMI) y en Cuesta de la Bajada (25\% del $\mathrm{NMI}$ ), lo que parece evidenciar la influencia climática mediterránea en ambas regiones.

Las indicaciones paleoambientales de medio y clima que se desprenden de la asociación de micromamíferos, son acordes con las que sugieren los macromamíferos del yacimiento de Cuesta de la Bajada (Santonja et al., 2014). Según estos autores (o.c.), la asociación de macromamíferos indica un clima templado; la abundancia del caballo sugiere un medio abierto con desarrollo de la vegetación herbácea y arbustiva; la presencia de Elephas (Palaeoloxodon) antiquus indica la existencia de masas de agua en las cercanías y zonas boscosas; y predominan las especies ecotonales que viven en los márgenes de bosques y praderas. Finalmente estos autores (o.c.) señalan que el yacimiento se formó en torno a una charca, no lejos del río.

\section{AGRADECIMIENTOS}

A Joaquín Panera, Susana Rubio y Pilar Punter, que de forma altruista se encargaron del lavado-tamizado de la gran cantidad de sedimento acumulado procedente de las primeras campañas realizadas por Étienne Moissenet. A todos los excavadores que han pasado durante todos estos años por el yacimiento y han ayudado de forma entusiasta a lavar sedimento y a triar el residuo resultante. A Joaquín Panera, Susana Rubio, Juan Antonio Martos, Ester Moreno y Laura Ramírez por todo el tiempo que han dedicado a triar durante todos estos años la gran cantidad de residuo resultante del lavado del sedimento del yacimiento. A José Ignacio Lorenzo, técnico de la Dirección General de Patrimonio Cultural del Gobierno de Aragón, por su gran ayuda en la gestión de las excavaciones. A Jaime Vicente y Carmen Escriche, que fueron directores del Museo de Teruel en distintos años alternativamente, por todas las facilidades que nos dieron y por habernos cedido las instalaciones del parque de bomberos de Teruel para realizar el lavado de sedimento durante todos estos años. En general, a todo el personal del Museo de Teruel que nos ha ayudado y atendido tan amablemente en numerosas ocasiones. A todas las personas del Parque de Bomberos de Teruel por habernos dejado utilizar sus instalaciones y material (mangueras, espacio para lavar con agua a presión, etc.) para el lavado de sedimento y su amabilidad al habernos facilitado el trabajo en todo momento; indudablemente al poner a nuestra disposición sus instalaciones, la eficacia y rapidez de realización del lavado de sedimento se multiplicó enormemente al disponer de potentes chorros de agua sin necesidad de utilizar una motobomba. A Francisco Javier Millán, periodista del Diario de Teruel, que de forma rigurosa y didáctica ha dado a conocer durante cada una de las campañas de excavación los hallazgos y resultados de nuestro trabajo en el yacimiento. A muchas personas de Teruel, especialmente al personal y residentes del Seminario Conciliar de Teruel, que con su cálida acogida han hecho que nuestras estancias veraniegas año tras año resultaran muy agradables en un entorno humano que llegó a sernos casi familiar. A Maite Alberdi, que señaló a unos de nosotros (C.S.) el posible error que había en varias publicaciones en las que aparecía citado Paraethomys meini en Huéscar 1, en lugar de en Huéscar 3 que era lo correcto, lo que ayudó a desentrañar el error, tal como se explica en el texto. A Robert Martin, de la Murray State University (EEUU): su reciente estancia en el departamento de Paleobiología del MNCN para revisar, entre otros, el material de arvicolinos del yacimiento de Huéscar 1, fue muy fructífera, como queda patente en el apartado correspondiente de este manuscrito. A los revisores del manuscrito: Xavier Murelaga y un revisor anónimo, al editor de la revista J.M. Cebriá, y a Robert Martin, por sus valiosas sugerencias al mismo. El Gobierno de Aragón autorizó las excavaciones y junto con el Museo de Teruel (Diputación Provincial de Teruel) financiaron las campañas de excavación. A todos ellos nuestro más sincero agradecimiento.

\section{Referencias}

Alberdi, M.T; Alonso, M.A.; Azanza, B. Hoyos, M. \& Morales, J. (2001). Vertebrate taphonomy in circum-lake environments: three cases in the Guadix-Baza Basin (Granada, Spain). Palaeogeography, Palaeoclimatology, Palaeoecology, 165 (1-2): 1-26. http://dx.doi.org/10.1016/ S0031-0182(00)00151-6

Altuna, J. (1972). Fauna de mamíferos de los yacimientos prehistóricos de Guipúzcoa. Con catálogo de los Mamíferos Cuaternarios del Cantábrico y del Pirineo Occidental. Munibe, 24, 1-464. 
Andrews, P. (1990). Owls, Caves and Fossils. The University of Chicago Press, $239 \mathrm{p}$.

Arribas, O. (2004). Fauna y paisaje de los Pirineos en la Era Glaciar. Lynx Edicions, Barcelona, $540 \mathrm{p}$.

Ayarzaguena, J. \& López Martínez, N. (1976). Estudio filogenético y comparativo de Microtus (I.) cabrerae y Microtus (I.) brecciensis. Doñana Acta Vertebrata, 3 (2): 181-204.

Berger, G.W.; Pérez-González, A.; Carbonell, E.; Arsuaga, J.L.; Bermúdez de Castro, J.M. \& Ku, T.L. (2008). Luminescence chronology of cave sediments at the Atapuerca paleoanthropological site, Spain. Journal of Human Evolution, 55 (2): 300-311. http://dx.doi.org/10.1016/j.jhevol.2008.02.012

Blanco, J.C. (1998). Mamíferos de España: I: Insectívoros, Quirópteros, Primates y Carnívoros de las Península Ibérica, Baleares y Canarias y II: Cetáceos, Artiodáctilos, Roedores y Lagomorfos de las Península Ibérica, Baleares y Canarias. Geoplaneta, Barcelona, 457 y 383 p.

Brunet-Lecomte, P. (1991). Repartition géographique des campagnols du genre Microtus (Arvicolidae, Rodentia) dans le nord-ouest Iberique. Archivos do Museu Bocage, Nova Série, 2 (2): 11-29.

Brunet-Lecomte, P.; Brochet, G.; Chaline, J. \& Delibes, M. (1987). Morphologie dentaire comparée de Pitymys lusitanicus et Pitymys duodecimcostatus (Arvicolidae, Rodentia) dans le nord-ouest de 1'Espagne. Mammalia, 51 (1): 145-158. http://dx.doi.org/10.1515/mamm.1987.51.1.145

Brunet-Lecomte, P. \& Chaline, J. (1990). Relations phylogénétiques et évolution des campagnols souterrains d'Europe (Terricola, Arvicolidae, Rodentia). Comptes Rendues de 1'Academie des Sciences de Paris, 311, Série II: 745-750.

Cabrera-Millet, M.; López Martínez, N. \& Michaux, J. (1982). Un exemple de lignée endémique iberoccitane, les campagnols Microtus brecciensis et Microtus cabrerae (Mammalia, Rodentia): Étude phylogénétique et contexte écologique d'un phénomène évolutif recent. In: Buffetaut, E.; Mazin, J. M. \& Salmon, E. (Eds.). Actes du symposium páleontologique G. Cuvier, Montbeliard, 69-83.

Carbonell, E.; Bermúdez de Castro, J.M.; Parés, J.M.; Pérez-González, A.; CuencaBescós, G.; Ollé, A.; Mosquera, M.; Huguet, R.; Made, J. van der; Rosas, A.; Sala, R.; Vallverdú, J.; García, N.; Granger, D.E.; Martinón-Torres, M.; Rodríguez, X.P.; Stock, G.M.; Vergès, J.M.; Allué, E.; Burjachs, F.; Cáceres, I.; Canals, A.; Benito, A.; Díez, C.; Lozano, M.; Mateos, A.; Navazo. M.; Rodríguez, J.; Rosell, J. \& Arsuaga, J.L. (2008). The first hominin of Europe. Nature, 452 (06815): 465-469. http://dx.doi.org/10.1038/ nature 06815

Chaline J. (1971). L'âge des Hominiens de la Caune de l'Arago à Tautavel (Pyrénées-Orientales), d'après l'étude des Rongeurs. Comptes Rendues de 1'Ácademie des Sciences de Paris, 272: 1743-1746.

Chaline J. (1972). Les Rongeurs du Pléistocène Moyen et Supérieur de France. (Systématique, Biostratigraphie, Paléoclimatologie). Cahiers de Paleontologie, C.N.R.S., Paris, 410 p.

Chaline, J.; Baudvin, H.; Jammot, D. \& Saint Girons, M.C. (1974). Les proies des rapaces. Petits Mammifères et leur environnement. Doin Ed., Paris, 141 p.

Chaline, J.; Brunet-Lecomte, P. \& Graf, J.-D. (1988). Validation de Terricola Fatio, 1867 pour les Campagnols souterrains (Arvicolidae, Rodentia) paléarctiques actuels et fossiles. Comptes Rendues de l'Academie des Sciences de Paris, Série III, 306: 475-478.

Chaline, J.; Brunet-Lecomte, P; Montuire, S.; Viriot, L. \& Courant F. (1999). Anatomy of the arvicoline radiation (Rodentia): palaeogeographical, palaeoecological history and evolutionary data. Annales Zoologici Fennici, 36: 239-267.

Cuenca-Bescós, G. \& \& Laplana, C. (1995). Evolución de Iberomys (Arvicolidae, Rodentia, Mammalia) durante el Cuaternario español. In: López, G.; Obrador, A. \& Vicens, E. (Eds.). XI Jornadas de Paleontología, Tremp, 69-72.

Cuenca-Bescós, G.; Canudo, J.I. \& Laplana, C. (1995). Los Arvicólidos (Rodentia, Mammalia) de los niveles inferiores de Gran Dolina (Pleistoceno Inferior, Atapuerca, Burgos, España). Revista Española de Paleontología, 10(2): 202-218.

Cuenca-Bescós, G.; Laplana, C. \& Canudo, J.I. (1999). Biochronological implications of the Arvicolidae (Rodentia, Mammalia) from the Lower Pleistocene hominid-bearing level of Trinchera Dolina 6 (TD6, Atapuerca, Spain). Journal of Human Evolution, 37 (3-4): 353-373. http://dx.doi.org/10.1006/ jhev. 1999.0306

Cuenca-Bescós, G.; Canudo, J.I. \& Laplana, C. (2001). La séquence des rongeurs (Mammalia) des sites du Pléistocène inférieur et moyen d'Atapuerca (Burgos, Espagne). L'Anthropologie, 105 (1): 115-130. http://dx.doi. org/10.1016/S0003-5521(01)80009-1

Cuenca-Bescós, G.; Agusti, J.; Lira, J.; Melero Rubio, M. \& Rofes, J. (2010). A new species of water vole from the Early Pleistocene of Southern Europe. Acta Palaeontologica Polonica, 55 (4): 565-580. http://dx.doi.org/10.4202/ app.2009.0027

Cuenca-Bescós, G.; López-García, J.M.; Galindo-Pellicena, M.A.; García-Perea, R.; Gisbert, J.; Rofes, J. \& Ventura, J. (2014). The Pleistocene history of
Iberomys, an endangered endemic rodent from South Western Europe. Integrative Zoology, 9: 481-497. http://dx.doi.org/10.1111/1749-4877.12053

Demuro, M.; Arnold, L.J.; Parés, J.M. \& Sala, R. (2015). Extended-range luminescence chronologies suggest potentially complex bone accumulation histories at the Early-to-Middle Pleistocene palaeontological site of Huéscar-1 (Guadix-Baza basin, Spain). Quaternary International, 389: 191-212. http:// dx.doi.org/10.1016/j.quaint.2014.08.035

Domínguez-Rodrigo, M.; Barba, R.; Soto, E.; Sesé, C.; Santonja, M.; PérezGonzález, A.; Yravedra, J. \& Galán, A. B. (2015). Another window to the subsistence of Middle Pleistocene hominins in Europe: A taphonomic study of Cuesta de la Bajada (Teruel, Spain). Quaternary Science Reviews, 126: 67-95. http://dx.doi.org/10.1016/j.quascirev.2015.08.020

Falguères, C.; Bahain, J.J.; Yokoyama, Y.; Arsuaga, J.L.; Bermúdez de Castro, J.M.; Carbonell, E.; Bischoff, J.L. \& Dolo, J.M. (1999). Earliest humans in Europe: the age of TD6 Gran Dolina, Atapuerca, Spain. Journal of Human Evolution, 37 (3-4): 343-352. http://dx.doi.org/10.1006/jhev.1999.0326

Fuentes, D.; Virgos, E.; García-Perea, R.; Garrido, J.A. \& Gisbert, J. (2013). Comparativa de métodos para estimas de regresión en el iberón (Iberomys cabrerae): implicaciones para su conservación. In: Libro de Resúmenes del XI Congreso de la Sociedad Española para la Conservación y el Estudio de los Mamíferos (SECEM), Avilés, Poster, p. 57.

García García, G. (1977). Micromamíferos del yacimiento achelense de la Solana de Zamborino, Fonelas (Granada). Tesis de Licenciatura, Universidad de Granada, $99 \mathrm{p}$

Garrido-García, J.A. \& Soriguer-Escofet, R.C. (2012). Cabrera's Vole Microtus cabrerae Thomas, 1906 and the subgenus Iberomys during the Quaternary: Evolutionary implications and conservation. Geobios, 45 (5): 437-444. http://dx.doi.org/10.1016/j.geobios.2011.10.014

Garrido-García, J.A.; Rosário, I.T.; Gisbert, J.; García-Perea, R.; Cordero, A.I.; López-Alabau, A.; Mathias, M. da L.; Mira, A.; Pita, R.; Santos, S.; SendraPérez, I.; Vicente, V. \& Soriguer, R.C. (2013). Revisión a nivel ibérico de la distribución del topillo de Cabrera o iberón, Iberomys cabrerae (Thomas, 1906). Galemys, 25: 35-49. http://dx.doi.org/10.7325/Galemys.2013.A4

García-Ibaibarriaga, N.; Murelaga Bereikua, X.; Bailon, S.; Rofes Chávez, J. \& Ordiales Castrillo, A. (2013). Estudio de los microvertebrados de la cueva de Arlanpe (Lemoa, Bizkaia). Kobie, Serie Bizkaiko Arkeologi Indusketak, 3, Bilbao, 81-110.

García-Ibaibarriaga, N.; Arrizabalaga, A.; Iriarte-Chiapusso, M.-J. ; Rofes, J. \& Murelaga, X. (2015). The return to the Iberian Peninsula: first Quaternary record of Muscardinus and a palaeogeographical overview of the genus in Europe. Quaternary Science Reviews, 119: 106-115. http://dx.doi. org/10.1016/j.quascirev.2015.04.017

Gibert, L.; Scott, G.; Martin, R. \& Gibert, J. (2007). The Early to Middle Pleistocene boundary in the Baza Basin (Spain). Quaternary Science Reviews, 26 (17-18): 2067-2089. http://dx.doi.org/10.1016/j.quascirev.2007.06.012

Gil, E. (1986). Taxonomía y bioestratigrafía de Micromamíferos del Pleistoceno Medio, especialmente Roedores, de los rellenos kársticos de la Trinchera de ferrocarril de la Sierra de Atapuerca (Burgos). Tesis Doctoral, Universidad de Zaragoza, $229 \mathrm{p}$.

Gil, E. (1996). Consideraciones bioestratigráficas sobre Allocricetus bursae (Cricetidae, Rodentia) en el Pleistoceno Inferior y Medio de Atapuerca (Burgos, España). Boletín Geológico y Minero, 107 (2): 145-152.

Gil, E. (1997). Bioestratigrafia y evolución de Microtus (I.) brecciensis en los yacimientos del Pleistoceno de Atapuerca (Burgos, España). Geogaceta, 21: 113-11. http://hdl.handle.net/10272/11046

Kowalski, K. (2001). Pleistocene rodents of Europe. Folia Cuaternaria, 72, 389 p.

Laplana, C. \& Sevilla, P. (2006). Nuevos datos sobre los micromamíferos (Roedores, Insectívoros y Quirópteros) del yacimiento Camino (Pleistoceno Superior, Pinilla del Valle, Madrid). In: Fernández Martínez, E. (Ed.). Libro de Resúmenes de las XXII Jornadas de Paleontología, León, 135-137.

Laplana, C. \& Sevilla, P. (2013). Documenting the biogeographic history of Microtus cabrerae through its fossil record. Mammal Review, 43 (4): 309-322. http://dx.doi.org/10.1111/mam.12003

Laplana, C.; Blain, H.A.; Sevilla, P.; Arsuaga, J.L.; Baquedano, E. \& PérezGonzález, A. (2013). Un assemblage de petits vertébrés hautement diversifié de la fin du MIS 5 dans un environnement montagnard au centre de l'Espagne (Cueva del Camino, Pinilla del valle, Communauté Autonome de Madrid). Quaternaire, 24 (2): 207-216. http://eprints.ucm.es/22644/

López-García, J.M. (2008). Evolución de la diversidad taxonómica de los micromamíferos en la Península Ibérica y cambios Paleoambientales durante el Pleistoceno Superior. Tesis Doctoral, Universitat Rovira i Virgili, 368 p., 13 Láms. http://hdl.handle.net/10803/8621

López-García, J.M.; Cuenca-Bescós, G.; Blain, H.-A.; Cáceres, I.; García, N. Made, J. van der; Gutiérrez, J.M.; Santiago, A. \& Giles Pacheco, F. (2012). Biochronological data inferred from the early Pleistocene Arvicolinae (Mammalia, Rodentia) of the El Chaparral site (Sierra del Chaparral, Cadiz, southwestern Spain). Journal of Vertebrate Paleontology, 32 (5): 1149-1156. http://dx.doi.org/10.1080/02724634.2012.676584 
López-García, J.M.; Berto, C.; Luzi, E.; Valle, Ch. dalla; Bañuls-Cardona, S. \& Sala, B. (2015). The genus Iberomys (CHALINE, 1972) (Rodentia, Arvicolinae, Mammalia) in the Pleistocene of Italy. Italian Journal of Geosciences, 134 (1): 162-169. http://dx.doi.org/10.3301/IJG.2014.48

López Martínez, N. (1980). Los micromamíferos (Rodentia, Insectivora, Lagomorpha y Chiroptera), del sitio de ocupación Achelense de Áridos-1 (Arganda, Madrid). In: Santonja, M.; López Martínez, N. \& PérezGonzález, A. (Eds.). Ocupaciones Achelenses en el Valle del Jarama (Arganda, Madrid). Arqueología y Paleoecología, 1. Diputación Provincial, Madrid, 161-202.

López Martínez, N. (1989). Revisión sistemática y biostratigráfica de los lagomorfos (Mammalia) del Terciario y Cuaternario de España. Memorias del Museo Paleontológico de la Universidad de Zaragoza, 3 (3), 343 p.

López Martínez, N. (2003). La búsqueda del centro de origen en biogeografía histórica. Graellsia, 59 (2-3): 503-522. http://dx.doi.org/10.3989/graellsia.2003.v59.i2-3.262

López Martinez, N. (2008). The Lagomorph Fossil Record and the Origin of the European Rabbit. In: Alves, P.C.; Ferrand, N. \& Hackländer, K., (Eds). Lagomorph Biology: Evolution, Ecology, and Conservation. Springer, Berlin, 27-46. http://dx.doi.org/10.1007/978-3-540-72446-9 3

López Martínez, N. \& Ruiz Bustos, A. (1977). Descubrimiento de dos yacimientos del Pleistoceno Medio en el karst de la Sierra Alfaguara (Granada): síntesis estratigráfica de este período en la región Bética. Estudios Geológicos, 33 (2): 255-265.

Made, J. van der; Aguirre, E.; Bastir, M.; Fernández Jalvo, J.; Huguet, R.; Laplana, C.; Márquez, B.; Martínez, C.; Martinón, M.; Rosas, A.; Rodríguez, J.; Sánchez, A.; Sarmiento, S. \& Bermúdez de Castro, J.M. (2003). El registro paleontológico y arqueológico de los yacimientos de la Trinchera del Ferrocarril en la Sierra de Atapuerca. Coloquios de Paleontología, Vol. Ext. 1, 345-372. http://hdl.handle.net/10261/8394

Martin, R.A. (2015). A brief review of the Spanish archaic Pleistocene arhizodont voles. Mastia: Revista del Museo Arqueológico Municipal de Cartagena, 11-13: 207-225

Masini, F.; Giannini, T.; Abbazzi, L.; Fanfani, F.; Delfino, M.; Maul, L.C. \& Torre, D. (2005). A latest Biharian small vertebrate fauna from the lacustrine succession of San Lorenzo (Sant'Arcangelo Basin, Basilicata, Italy). Quaternary International, 131 (1): 79-93. http://dx.doi.org/10.1016/j. quaint.2004.07.008

Maul, L.C.; Rekovets, L.; Heinrich, W.D.; Keller, T. \& Storch, G. (2000). Arvicola mosbachensis (SCHMIDTGEN 1911) of Mosbach 2: a basic sample for the early evolution of the genus and a reference for further biostratigraphical studies. Senckenbergiana Lethaea, 80 (1): 129-147. http://dx.doi. org/10.1007/BF03043667

Mazo, A.V.; Sesé, C.; Ruiz Bustos, A. \& Peña, J.A. (1985). Geología y Paleontología de los yacimientos plio-pleistocenos de Huéscar (Depresión de Guadix-Baza, Granada). Estudios Geológicos, 41: 467-493. http://hdl.handle. net/10261/13387

Michaux, J. \& Pasquier, L. (1974). Dynamique des populations de Mulots (Rodentia, Apodemus) en Europe durant le Quaternaire. Premières données. Bulletin de la Société Géologique de France, 16 (4): 431-439. http://dx.doi. org/10.2113/gssgfbull.S7-XVI.4.431

Minwer-Barakat, R.; Madurell-Malapeira, J.; Alba, D.M.; Aurell-Garrido, J.; Esteban-Trivigno, D. de \& Moyà-Solà, S. (2011). Pleistocene rodents from the Torrent de Vallparadis section (Terrassa, northeastern Spain) and biochronological implications. Journal of Vertebrate Paleontology, 31 (4): 849-865. http://dx.doi.org/10.1080/02724634.2011.576730

Mitchell-Jones, A.J.; Amori, G.; Bogdanowicz, W.; Krystufek, B.; Reijnders, P.J.H.; Spitzenberger, F; Stubbe, M.; Thissen, J.B.M.; Vohralík, V. \& Zima, J. (1999). The Atlas of European Mammals. Academic Press. T \& AD Poyser Ltd. UK, London, $484 \mathrm{p}$.

Moissenet, E. (1993). L'áge et les déformations des terrases alluviales du Fossé de Teruel. El Cuaternario en España y Portugal. Actas de la II Reunión del Cuaternario Ibérico. ITGE \& AEQUA, Madrid, 267-279.

Moreno, D.; Falguères, C.; Pérez-González, A.; Voinchet, P.; Ghaleb, B.; Despriée; J.; Bahain, J.J.; Sala, R.; Carbonell, E.; Bermúdez de Castro, J.M. \& Arsuaga, J.L. (2015). New radiometric dates on the lowest stratigraphical section (TD1 to TD6) of Gran Dolina site (Atapuerca, Spain). Quaternary Geochronology, 30B: 535-540. http://dx.doi.org/10.1016/j. quageo.2015.05.007

Niethammer, J.; Niethammer, G. \& Abs, M. (1964). Ein Beitrag zur Kenntnis der Cabreramaus (Microtus cabrerae Thomas, 1906). Bonner Zoologische Beiträge, $15(3-4): 127-148$

Ollé, A.; Mosquera, M.; Rodríguez, X.P.; Lombera-Hermida, A. de; García-Antón, M.D.; García-Medrano, P.; Peña, L.; Menéndez L.; Navazo, M.; Terradillos, M.; Bargalló, A.; Márquez, B.; Sala, R. \& Carbonell, E. (2013). The Early and Middle Pleistocene technological record from Sierra de Atapuerca (Burgos, Spain). Quaternary International. 295: 138-167. http://dx.doi. org/10.1016/j.quaint.2011.11.009
Palomo, L.J. \& Gisbert, J. (Eds.) (2002). Atlas de los Mamíferos terrestres de España. Dirección General de Conservación de la Naturaleza \& SECEM \& SECEMU, Madrid, $564 \mathrm{p}$

Panera, J.; Torres, T.; Pérez-González, A.; Ortiz, J.E.; Rubio-Jara, S. \& Uribelarrea del Val, D. (2011). Geocronología de la Terraza Compleja de Arganda en el valle del río Jarama (Madrid, España). Estudios Geológicos, 67 (2): 495504. http://dx.doi.org/10.3989/egeol.40550.204

Pasquier, L. (1974). Dynamique évolutive d'un sous-genre de Muridae, Apodemus (Sylvaemus). Etude biometrique des caractères dentaires des populations fossiles et actuelles d'Europe Occidentale. Thèse, Université des Sciences et Techniques du Lanquedoc, Montpellier, $184 \mathrm{p}$.

Paunesco, A.C. \& Brunet-Lecomte, P. (2005). Analyse odontométrique du sousgenre Microtus (Iberomys) Chaline, 1972 (Rodentia, Arvicolinae) du sud de la France au Pléistocène moyen et supérieur. Bulletin du Musée d'Anthropologie Prehistorique de Monaco, 45: 31-39.

Pemán, E. (1985). Aspectos climáticos y ecológicos de los Micromamíferos del yacimiento de Erralla. Munibe, Antropologia-Arkeologia, 37: 49-57.

Pita, R.; Mira, A. \& Beja, P. (2014). Microtus cabrerae (Rodentia: Cricetidae). Mammalian Species, 46 (912): 48-70. http://dx.doi.org/10.1644/912.1

Rekovets, L. \& Nadachowski, A. (1995). Pleistocene Voles (Arvicolidae) of the Ukraine. Paleontologia I Evolució, 28-29: 145-245.

Rodríguez, J.; Burjachs, F.; Cuenca-Bescós, G.; García, N.; Made, J. van der; Pérez González, A.; Blain, H.A.; Expósito, I.; López-García, J.M.; García Antón, M.; Allué, E.; Cáceres, I.; Huguet, R.; Mosquera, M.; Ollé, A.; Rosell, J.; Parés, J.M.; Rodríguez, X.P.; Díez, C.; Rofes, J.; Sala, R.; Saladié, P.; Vallverdú, J.; Bennasar, M.L.; Blasco, R.; Bermúdez de Castro, J.M. \& Carbonell, E. (2011). One million years of cultural evolution in a stable environment at Atapuerca (Burgos, Spain). Quaternary Science Reviews, 30 (11-12): 1396-1412. http://dx.doi.org/10.1016/j.quascirev.2010.02.021

Rodríguez Prieto, A. (2013). Filogenia, morfometría y especiación de dos topillos ibéricos: Microtus duodecimcostatus y Microtus lusitanicus. Tesis Doctoral, Universitat de Barcelona, 181 p. http://hdl.handle.net/2445/49025

Rofes, J.; García-Ibaibarriaga, N.; Murelaga, X.; Arrizabalaga, A.; Iriarte, M.-J.; Cuenca-Bescós, G. \& Villaluenga, A. (2012). The southernmost record of Sicista (Mammalia; Dipodidae) in Eurasia, with a review of the palaeogeography and palaeoecology of the genus in Europe. Palaeogeography, Palaeoclimatology, Palaeoecology, 348-349: 67-73. http://dx.doi. org/10.1016/j.palaeo.2012.06.016

Rosas, A.; Huguet, R.; Pérez-González, A.; Carbonell, E.; Bermúdez de Castro, J.M.; Vallverdú, J.; Made, J. van der; Allué, E.; García, N.; Martínez-Pérez, R.; Rodríguez, J.; Sala, R.; Saladie, P.; Benito, A.; Martínez-Maza, C.; Bastir, M.; Sánchez, A. \& Parés, J.M. (2006). The "Sima del Elefante" cave site at Atapuerca (Spain). Estudios Geológicos, 62 (1): 327-348. http://dx.doi. org/10.3989/egeol.0662129

Ruiz Bustos, A. (1988). Estudio sobre los arvicólidos cuaternarios. Paleomammalia, 2 (1): 89 p.; 6 Láms; 1 Tabla.

Ruiz Bustos, A. \& Michaux, J. (1976). Le site préhistorique nouveau de Cullar de Baza-I (Province de Grenade, Espagne) d'âge pléistocène moyen. Etude préliminaire et analyse de la fauna des Rongeurs. Géologie méditerranéenne, 2 (3): $173-182$

Ruiz Bustos, A. \& García Sánchez, M. (1977). Las condiciones ecológicas del Musteriense en las depresiones granadinas. La fauna de micromamíferos en la Cueva de la Carigüela (Piñar, Granada). Cuadernos de Prehistoria y Arqueología de la Universidad de Granada, 2: 7-17.

Ruiz Bustos, A.; Toro Moyano, I.; Martín Suárez, E. \& Almohalla Gallego, M. (1982). Procesos evolutivos durante el Cuaternario medio y superior en las poblaciones de pequeños mamíferos del sur de la Península Ibérica. Condiciones climáticas que implican e importancia biostratigráfica. Cuadernos de Prehistoria de la Universidad de Granada, 7: 9-35.

Santonja, M.; Moissenet, E. \& Pérez-González, A. (1990). El yacimiento paleolítico inferior de Cuesta de la Bajada (Teruel): noticia preliminar. In: Arqueología Aragonesa, 1990. Diputación General de Aragón, Zaragoza, 21-25.

Santonja, M.; Moissenet, E. \& Pérez-González, A. (1992). Cuesta de la Bajada (Teruel), Nuevo sitio paleolítico inferior. Boletín del Seminario de Arte y Arqueología, 58, 5-46. http://uvadoc.uva.es/handle/10324/11129

Santonja, M.; Moissenet, E.; Pérez-González, A.; Villa, P.; Sesé, C.; Soto, E; Eisenman, V.; Mora, R. \& Dupré, M., (1994). Cuesta de la Bajada: un yacimiento del Pleistoceno medio en Aragón. In: Royo Guillén, J.I. (Coord.). Arqueología Aragonesa, 1994: 61-68.

Santonja, M; Villa, P.; Pérez-González, A.; Sesé, C. \& Mora, R. (1996). Site setting and assemblage variability in the late Middle Pleistocene of the Iberian Peninsula: Evidence from Cuesta de la Bajada, a new site in the Aragon Region. XIII International Congress of Prehistoric Sciences, Abstracts, v. 2, Forli, p. 44.

Santonja, M.; Pérez-González, A.; Villa, P.; Sesé, C.; Soto, E.; Mora, R.; Eisenmann, V. \& Dupré, M. (2000). El yacimiento paleolítico de Cuesta de la Bajada (Teruel) y la ocupación humana de la zona oriental de la Península Ibérica en el Pleistoceno medio. In: Olcina Domenech, M.H.; Soler Díaz, 
J.A. (Coords.). Scripta in Honorem Enrique A. Llobregat Conesa. Instituto Alicantino de Cultura "Juan Gil-Albert", Alicante, 79-101. http://hdl. handle.net/10261/76791

Santonja, M. \& Pérez-González, A. (2001). Cuesta de la Bajada (Teruel) and Human occupation of the Eastern zone of the Iberian Peninsula in the Middle Pleistocene. In: Büchner, D. (Ed.). Studien in Memoriam Wilhelm Schüle. Freiburger Institut für Paläowissenschaftliche Studien \& M. Leidorf Pub., Freiburg, 418-426.

Santonja, M. \& Pérez-González, A. (2010). Mid-Pleistocene Acheulian industrial complex in the Iberian Peninsula. Quaternary International: 223-224: 154161. http://dx.doi.org/10.1016/j.quaint.2010.02.010

Santonja, M.: Pérez-González, A.; Domínguez-Rodrigo, M.; Panera, J.; Rubio-Jara, S.; Sesé, C.; Soto, E.; Arnold, L.J.; Duval, M.; Demuro, M.; Ortiz, J.E.; Torres, T. de; Mercier, N.; Barba, R. \& Yravedra, J. (2014). The Middle Paleolithic site of Cuesta de la Bajada (Teruel, Spain): a perspective on the Acheulean and Middle Paleolithic technocomplexes in Europe. Journal of Archaeological Science, 49: 556-571. http://dx.doi.org/10.1016/j.jas.2014.06.003

Sesé, C. (1989). Micromamíferos del Mioceno, Plioceno y Pleistoceno de la cuenca de Guadix-Baza (Granada). In: Alberdi, M.T. \& Bonadonna, F.P. (Eds.). Geología y Paleontología de la Cuenca de Guadix-Baza. Trabajos sobre el Neógeno-Cuaternario, 11. MNCN, CSIC, 185-214. http://hdl. handle.net $/ 10261 / 3213$

Sesé, C. (1994). Paleoclimatical interpretation of the Quaternary small Mammals of Spain. Geobios. 27 (6): 753-767. http://dx.doi.org/10.1016/ S0016-6995(94)80060-X

Sesé, C. (2005). Aportación de los micromamíferos al conocimiento paleoambiental del Pleistoceno Superior de la Región Cantábrica: nuevos datos y síntesis. In: Montes Barquín, R. \& Lasheras Corruchaga, J.A. (Eds.). Neandertales Cantábricos, estado de la cuestión. Monografías del Museo Nacional y Centro de Investigación de Altamira, 20: 167-200.

Sesé, C. (2006). Los roedores y lagomorfos del Neógeno de España. Estudios Geológicos, 62 (1): 429-480. http://dx.doi.org/10.3989/egeol.0662138
Sesé, C. (2007). Micromamíferos (Rodentia, Insectivora, Lagomorpha y Chiroptera) de La Peña de Estebanvela (Segovia). In: Cacho, C.; Ripoll, S. \& Muñoz, F. (Coords.). La Peña de Estebanvela (Estebanvela-Ayllón, Segovia): Grupos Magdalenienses en el Sur del Duero. Memorias. Arqueología en Castilla y León, Valladolid, 17: 145-165. http://hdl.handle.net/10261/3423

Sesé, C. \& Gil, E. (1987). Los Micromamíferos del Pleistoceno medio del complejo kárstico de Atapuerca (Burgos). In: Aguirre, E.; Carbonell, E. \& Bermúdez de Castro, J. M. (Eds.). El hombre fósil de Ibeas y el Pleistoceno de la Sierra de Atapuerca, I. Junta de Castilla y León, Valladolid, 75-88.

Sesé, C. \& Soto, E. (1988). Los Micromamíferos (Rodentia, Insectivora y Lagomorpha). In: Ripoll López, S. (Ed.). La Cueva de Ambrosio (Almería, Spain) y su posición cronoestratigráfica en el Mediterráneo occidental. BAR International Series, 462 (I), 157-168.

Sesé, C. \& Sevilla, P. (1996). Los Micromamíferos del Cuaternario español: cronoestratigrafia e implicaciones biostratigráficas. Revista Española de Paleontología, $\mathrm{n}^{\circ}$ extraordinario: 278-287. http://hdl.handle.net/10261/3179

Sesé, C.; Panera, J.; Rubio-Jara, S. \& Pérez-González, A. (2011a). Micromamíferos del Pleistoceno Medio y Pleistoceno Superior en el valle del Jarama: yacimientos de Valdocarros y HAT (Madrid, España). Estudios Geológicos, 67 (1): 131-151. http://dx.doi.org/10.3989/egeol.40290.127

Sesé, C.; Rubio-Jara, S.; Panera, J. \& Pérez-González, A. (2011b). Micromammals from the Late Pleistocene site of PRERESA in the Manzanares valley and its contribution to the paleoenvironmental reconstruction of the Madrid basin during the Pleistocene. Estudios Geológicos, 67(2): 471-494. http:// dx.doi.org/10.3989/egeol.40516.203

Sesé, C. \& López Martínez, N. (2013). Nuevos datos paleontológicos del Pleistoceno en el Valle del Manzanares (Madrid, España): Los micromamíferos del yacimiento del Arenero de Arriaga. Estudios Geológicos, 69 (2): 271-282. http://dx.doi.org/10.3989/egeol.41318.270

Toni, I. \& Molero, G. (1990). Los roedores (Rodentia, Mammalia) del yacimiento cuaternario de Pinilla del Valle (Madrid). Actas de las IV Jornadas de Paleontología, Salamanca, 1988: 359-373. 